\title{
Novel necroptosis-related gene signature for predicting the prognosis of pancreatic adenocarcinoma
}

\author{
Zixuan $\mathrm{Wu}^{1}{ }^{1}$, Xuyan Huang ${ }^{1}$, Minjie $\mathrm{Cai}^{2}$, Peidong Huang ${ }^{3}$, Zunhui Guan ${ }^{4}$ \\ ${ }^{1}$ Guangzhou University of Chinese Medicine, Guangzhou, Guangdong Province 510006, China \\ ${ }^{2}$ Shantou Health School, Shantou, Guangdong Province 515061, China \\ ${ }^{3}$ Yunnan University of Chinese Medicine, Kunming, Yunnan Province 650500, China \\ ${ }^{4}$ Kunming Municipal Hospital of Traditional Chinese Medicine, Kunming, Yunnan Province 650011, China
}

Correspondence to: Peidong Huang; email: huangpeidong@ynutcm.edu.cn

Keywords: pancreatic adenocarcinoma (PAAD), necroptosis-related genes (NRGs), TCGA and GEO datasets, immunity, m6A and immune checkpoint, bioinformatics analysis

Received: November 4, $2021 \quad$ Accepted: January 11, $2022 \quad$ Published: January 24, 2022

Copyright: $(2022 \mathrm{Wu}$ et al. This is an open access article distributed under the terms of the Creative Commons Attribution License (CC BY 3.0), which permits unrestricted use, distribution, and reproduction in any medium, provided the original author and source are credited.

\begin{abstract}
Pancreatic adenocarcinoma (PAAD) is a deadly digestive system tumor with a poor prognosis. Recently, necroptosis has been considered as a type of inflammatory programmed cell death. However, the expression of necroptosis-related genes (NRGs) in PAAD and their associations with prognosis remain unclear. NRGs' prediction potential in PAAD samples from The TCGA and GEO datasets was investigated. The prediction model was constructed using Lasso regression. Co-expression analysis showed that gene expression was closely related to necroptosis. NRGs were shown to be somewhat overexpressed in high-risk people even when no other clinical symptoms were present, indicating that they may be utilized in a model to predict PAAD prognosis. GSEA showed immunological and tumor-related pathways in the high-risk group. Based on the findings, immune function and m6A genes differ significantly between the low-risk and high-risk groups. MET, AM25C, MROH9, MYEOV, FAM111B, Y6D, and PPP2R3A might be related to the oncology process for PAAD patients. Moreover, CASKIN2, TLE2, USP20, SPRN, ARSG, MIR106B, and MIR98 might be associated with low-risk patients with PAAD. NRGs and the relationship of the immune function, immune checkpoints, and m6A gene expression with NRGs in PAAD may be considered as potential therapeutic targets that should be further studied.
\end{abstract}

\section{INTRODUCTION}

Pancreatic adenocarcinoma (PAAD) is considered as a fatal gastrointestinal tumor globally, with a death rate that is comparable to its incidence [1]. Surgical resection is the only drastic therapy, but the prognosis is dismal. Primary screening of high-risk factors of PAAD has no standard. By contrast, CT, MRI, positron emission tomography/computed tomography is utilized to diagnose PAAD [2]. However, most patients with PPAD are already in advanced stages, and they have missed the opportunity for surgical treatment after being diagnosed. The curative impact of radiation and chemotherapy for PAAD is not precise [3]. Considering that molecularly targeted therapy has become an indispensable method of treating malignant tumors, identifying novel therapeutic targets is critical.

Apoptosis resistance is a significant barrier that causes chemotherapy to fail during cancer treatment. Bypassing the apoptotic pathway to increase cancer cell death can be performed to address this problem $[4,5]$. When apoptosis cannot occur properly, the cell will die. Necrosis is initiated as a "substitute" for apoptosis [6]. It is a caspase-independent, regulated necrotic cell death mechanism primarily mediated by receptor-interacting Protein 1 (RIP1), RIP3, and mixed lineage kinase 
domain-like protein (MLKL) [7]. Necrotic cells will expel their contents, stimulating the inflammatory response of the surrounding cells and activating body's immunological response. Consequently, cell necrosis plays a significant role in tumorigenesis, metastasis, and infectious and inflammatory disorders [8, 9]. Necroptosis promotes cancer spread, although it could suppress cancer [10-12]. However, only a few sequence-based studies on aberrant gene expression and its relationship with overall survival (OS) in PAAD patients with necroptosis have been conducted.

Immune checkpoint-related gene profiles in patients with PAAD may be used to identify, evaluate, and

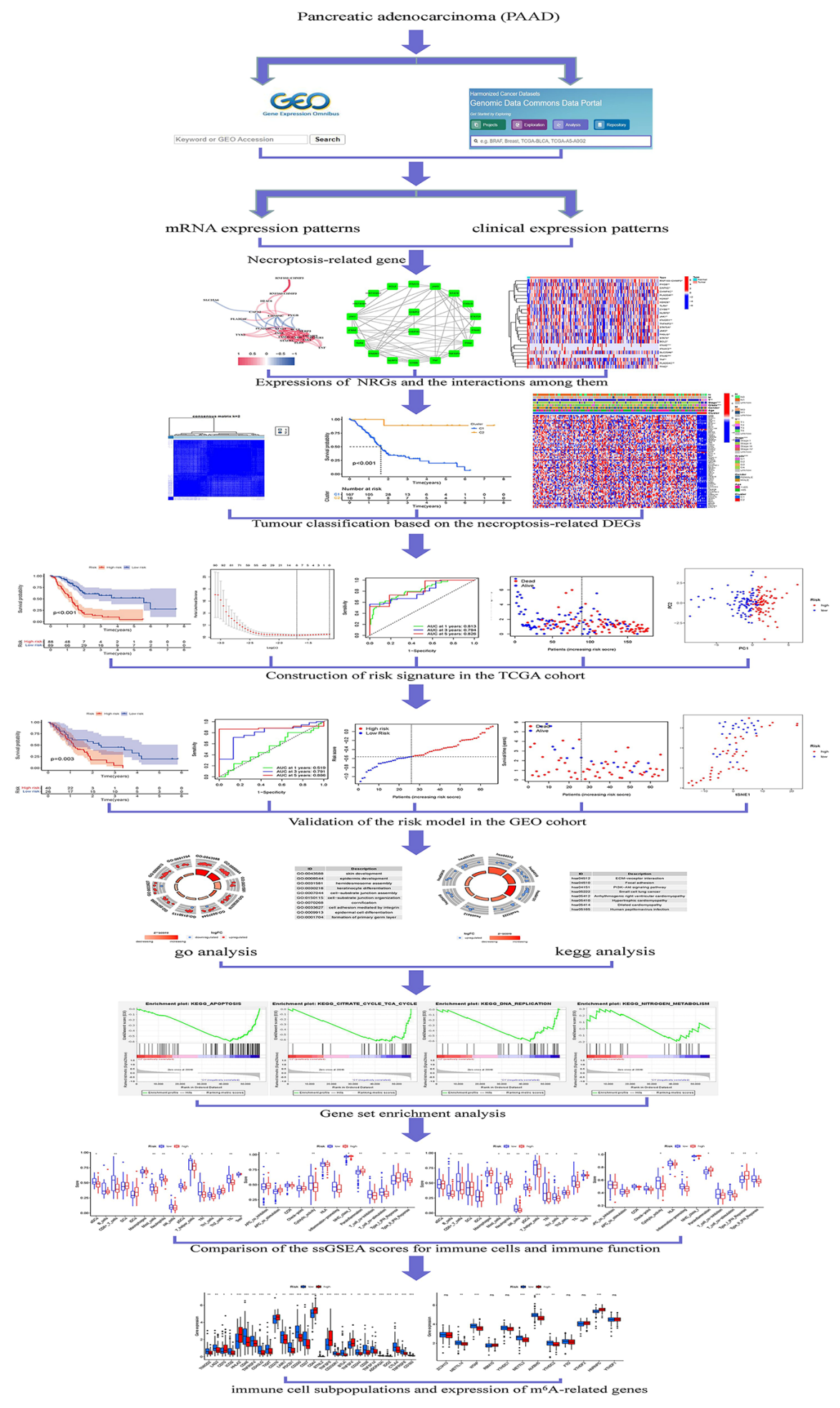

Figure 1. Framework based on an integration strategy of NRGs. 
predict treatment responses [13]. Despite little analysis conducted on the link between NRGs and PAAD, studying the interaction between NRGs, immunity, immunological checkpoints, and m6A with PAAD clinicopathological tumor options is important. The cause and mechanism of PAAD's abnormal gene expression and necroptosis are unknown. Further research on the altered transcription of NRGs in patients with PAAD is required to investigate the influence of the NRGs pathway on the prognosis of patients with PAAD. Therefore, understanding the impact of NRGs on PAAD development may find a biomarker that might be utilized as a therapeutic target.

This study aimed to form a prognostic model for PAAD prognosis by spotting NRGs expression related to PAAD patient prognosis. Comprehensively understanding the invasion of NRGs and their associated targets, innovative PAAD therapeutic targets and pharmacologic approaches will be developed. The strategy of NRGs is shown in Figure 1.

\section{MATERIALS AND METHODS}

We followed the methods of Ying Ye et al. 2021 [14].

\section{Datasets and NRGs}

PAAD gene expression patterns and clinical data were collected from the Cancer Genome Atlas (TCGA) [15]. In September 30, 2021, the data of 181 PAAD and 4 normal tissues were enrolled in the TCGA. The Gene Expression Omnibus (GEO) was searched for micro data on mRNA expression. Series: GSE62452. Platform: GPL6244. The GEO shared database was used to maintain the expression patterns of 130 PAAD cases (Table 1). In addition, 52 NRGs were identified from KEGG (https://www.kegg.jp/kegg/) (Supplementary Table 1).

\section{Annotation of genes, identification of NRGs and its mutation rates}

Transcription and human configuration data were matched by Perl to obtain the precise mRNA gene expression data. The gene IDs were transformed into gene names by R4.1.0 [16]. In order to evaluate the difference of NRGs expression (DEGs) with statistical significance, FDR $<0.05$ and $|\log 2 \mathrm{FC}| \geq 0.585$ as a selection criteria. DEG mutation rates were examined using Cbioportal [17] (http://www.cbioportal.org/).

\section{Tumor classification based on DEGs}

First, prognosis-related NRGs were classified into two groups: cluster 1 and 2. Survminer and survival were used to explore the survival and predictive value of PRG subtypes. pheatmap was used to construct a heatmap showing the differential expression and the relationship between NRGs and clinicopathological features of NRGs in each cluster. Limma and corrplot were used to explore the gene connection between PAAD target genes and prognostic NRGs.

\section{Development of NRGs prognostic signature}

The DEGs were split into two classes that supported the median score: low-and high-risk. Lasso regression was related to two classes, and the boldness interval and risk ratio were computed. Survival curves for the two groups were generated and compared. timeROC was used to provide a comparable receiver-operating characteristic (ROC) curve to evaluate the accuracy of this model for predicting survival in PAAD. For the chance curve bestowed by the risk score, NRGs' risk and survival status were examined. The relationship between clinical characteristics and risk-model was determined, and a similar relationship was found between two NRGs patients. Analyses of risk and clinical relationships are distributed. In addition, investigation was performed using principal component analysis (PCA) and T-distributed neighbor embedding (T-SNE) to analyze whether the prognostic model might properly categorize patients into two risk teams [18]. Desegregating the prognosticative signals, a representation was developed to predict 1-, 3-, and 5year OS of patients with PAAD.

\section{Functional enrichment of differentially expressed NRGs}

The biological pathways associated with the TCGA DEGs were then examined using Gene Ontology (GO). Biological processes (BP), molecular functions (MF), and cellular components (CC) are controlled by differentially expressed NRGs. NRGs were further investigated using R based on KEGG data [19].

\section{GSEA enrichment analyses and predictive nomogram}

GSEA was used to find related functions and pathway variations. The associated score and graphs were used to verify whether the functions and routes within different risk groups were dynamic. Every sample was classified as "H" or "L" based on whether it had been a high-risk cluster of prognosis-related NRGs.

\section{Comparison of immune activity among subgroups}

Analysis of single-sample sequence set enrichment was utilized (ssGSEA). The enrichment score of immune cells and immune-related activities in two groups was examined in each TCGA and GEO cohort. In addition, 
Table 1. Clinical characteristics.

\begin{tabular}{lclc}
\hline \multicolumn{2}{c}{ TCGA } & & \multicolumn{2}{c}{ GEO } \\
\hline Variables & Number of samples & Variables & Number of samples \\
\hline Gender & & Gender & \\
Male/Female & $102 / 83$ & Male/Female & Unknown \\
Age at diagnosis & & Age at diagnosis & \\
$\leq 65 />65$ & $96 / 89$ & $\leq 65 />65$ & Unknown \\
Grade & & Grade & \\
G1/G2/G3/G4/NA & $32 / 97 / 51 / 2 / 3$ & G1/G2/G3/G4/NA & $3 / 64 / 59 / 2 / 2$ \\
Stage & & Stage & \\
I/II/III/IV/NA & $21 / 152 / 4 / 5 / 3$ & I/II/III/IV/NA & $7 / 84 / 26 / 13 / 6$ \\
T & & $\mathrm{T}$ & \\
T1/T2/T3/T4/NA & & T1/T2/T3/T4 & Unknown \\
M & $7 / 24 / 148 / 4 / 2$ & $\mathrm{M}$ & \\
M0/M1/NA & & $\mathrm{M} 0 / \mathrm{M} 1 / \mathrm{NA}$ & Unknown \\
$\mathrm{N}$ & $85 / 5 / 95$ & $\mathrm{~N}$ & Unknown \\
$\mathrm{N} 0 / \mathrm{N} 1 / \mathrm{N} 2$ & & $\mathrm{~N} 0 / \mathrm{N} 1 / \mathrm{N} 2 / \mathrm{N} 3$ & \\
\hline
\end{tabular}

the connection among NRGs, checkpoints, and m6A were investigated because these NRGs had significant therapeutic implications.

\section{Data availability}

Patients who granted informed consent to use their data have been uploaded to the public-accessible TCGA and GEO databases.

\section{Ethics approval and consent to participate}

This manuscript is not a clinical trial; hence, ethics approval and consent to participate is not applicable.

\section{RESULTS}

\section{Differentially expressed NRGs}

We found 25 DEGs related to TCGA (7 upregulated, 18 downregulated; Figure 2A, Supplementary Table 2). We performed a protein-protein interaction (PPI) study to investigate NRGs' interactions, and the findings are presented in Figure 2B. We discovered that JAK1, TNF, JAK3, IFNGR1, TLR4, and TYK2 were hub genes by setting the low necessary interaction value to 0.4 . (Supplementary Table 3). These genes, which included all DEGs discovered in normal and malignant tissues, may be used to determine independent PAAD prognostic markers. Figure $2 \mathrm{C}$ demonstrates the correlation network, which includes all NRGs. We investigated genetic changes in these NRGs because of their important clinical implications. We found that the two common mutations were truncating and missense mutations (Figure 3). A total of 9 genes had a 3\% mutation rate, with IFNA2, IFNA6, and IFNA13 being the commonly altered (17\%).

\section{Tumor classification based on the DEGs}

According to Consensus clustering analysis, when the clustering variable $(\mathrm{k})$ was set to 2 , the intragroup correlations were the highest, and the intergroup correlations were the lowest, indicating that the 181 PAAD patients could be separated into two groups (Figure 4A). Consequently, DEGs were divided into two clusters: cluster 1 and 2. The gene expression profile and clinical features were shown using a heatmap (Figure 4B). Survival research was conducted to evaluate the prognostic value of NRGs, and the survival rate of cluster 2 was higher than that of cluster $1(P<0.001$, Figure 4C).

\section{Development of a prognostic gene model in the TCGA cohort}

We incorporate the TCGA cohort in the training group and the GEO Cohort in the test group to improve the accuracy of the prognostic model. The university COX study identified 10 significant NRGs, which were then included in multivariate $\mathrm{COX}$ analysis. A total of 10 NRGs were identified as independent PAAD prognostic markers (MET, CASKIN2, TLE2, USP20, MROH9, SPRN, ARSG, ARNTL2, ANLN, LY6D; 
Figure 5A). A gene signature was created using the absolute minimal shrinkage and selection operator (LASSO) Cox regression analysis and optimal value (Figure 5B, 5C). We discovered that the risk score of patients was negatively connected to the survival of patients with PAAD. Most of the new NRGs discovered in this investigation showed a negative relationship with the risk model, indicating that additional research is necessary (Figure 5D). Based on Kaplan-Meier analysis, the presence of high-risk PRG signatures was linked with a decreased chance of survival $(P<0.001$, Figure 5E). For 1,3 , and 5-year survival rates, the AUC predictive value of the unique NRGs signature was $0.813,0.794$, and 0.826, respectively (Figure 5F). The PCA and t-SNE results showed that patients with varying risks were divided into two groups (Figure 5G, 5H).

\section{External validation of the risk signature}

A GEO cohort of 130 PAAD patients served as the validation group. We discovered that patient's risk score

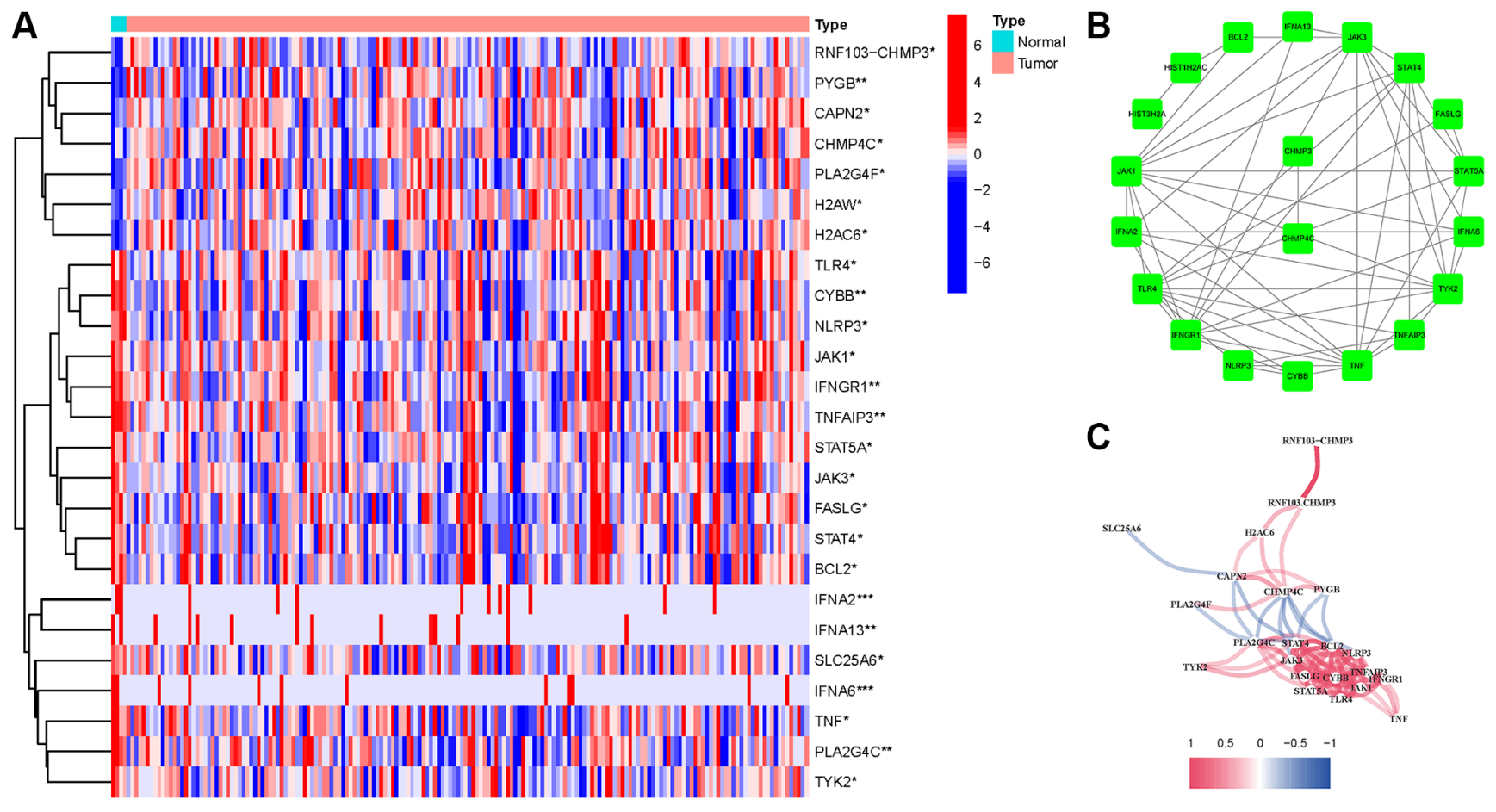

Figure 2. Expressions of the $\mathbf{2 5}$ NRGs and their interactions. (A) Heatmap. (B) PPI network. (C) Correlation network (red: positive; blue: negative).

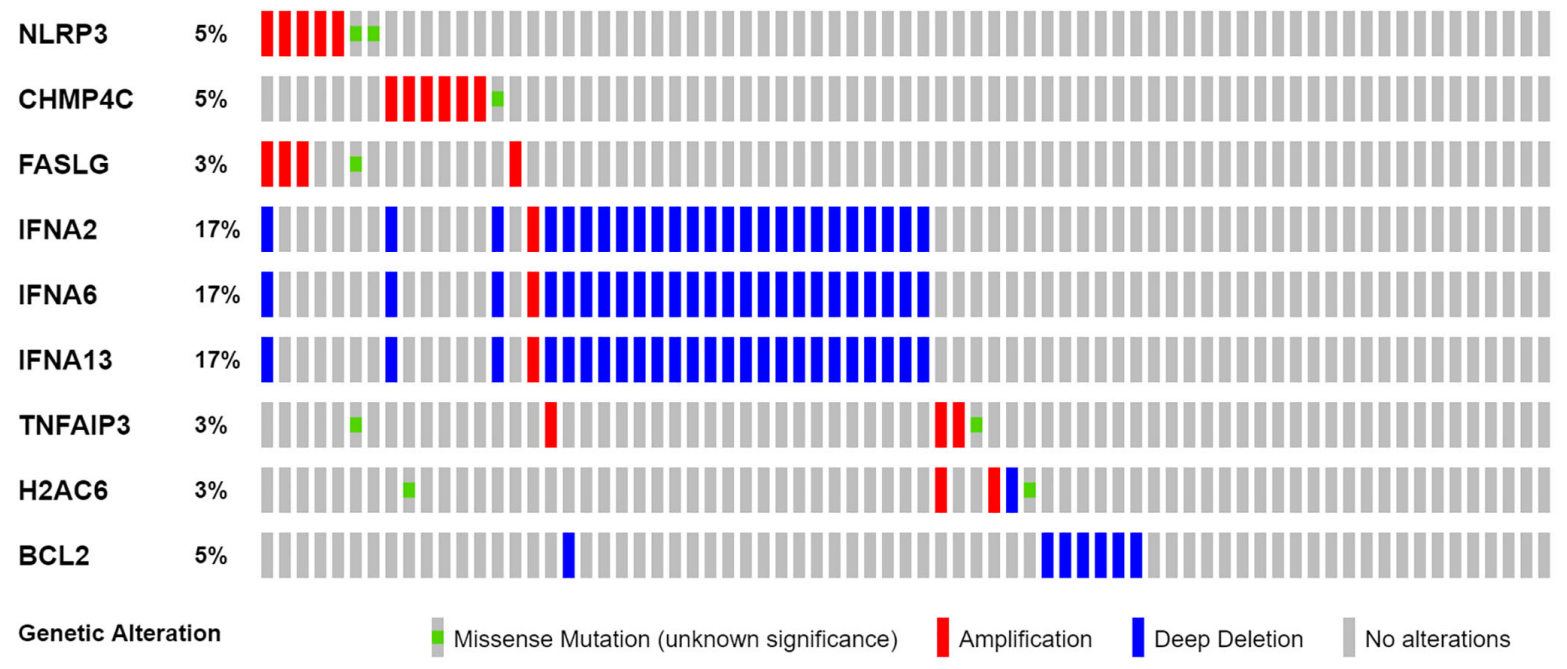

Figure 3. Mutations in NRGs (Abbreviations: N: normal; T: tumor). 
was negatively related to the survival of patients with PAAD. Similar to the TCGA findings, most of the novel NRGs discovered in this investigation were adversely linked with the risk model (Figure 6A). The presence of high-risk PRG signatures was associated with a lower likelihood of survival $(P=0.003)$. KaplanMeier analysis was utilized to create Figure 6B. The AUC predictive value of the unique NRGs signature was $0.519,0.791$, and 0.886 for 1,3 , and 5-year survival rates, respectively (Figure 6C). The results of PCA and t-SNE revealed that patients with varied risks were well divided into two groups (Figure 6D, 6E).

\section{Independent prognostic value of the risk model}

COX analysis in the TCGA cohort revealed that the NRGs signature (HR: 37.625, 95CI: 15.601-90.741) was the primary independent predictor of OS of patients with PAAD (HR: 37.625, 95CI: 15.601-90.741; Figure 7A, 7B). The COX analysis result was demonstrated in the GEO cohort (Figure 7C, 7D). In addition, we created a heatmap of clinical features for the TCGA cohort (Figure 7E, Supplementary Table 4).

\section{Enrichment analysis of necroptosis-related genes}

GO enrichment analysis revealed 83 core targets, including $\mathrm{CC}$ and $\mathrm{BP}$. The $\mathrm{CC}$ primarily involves the cell-substrate junction (GO:0030055), endoplasmic reticulum lumen (GO:0005788), and basal part of cell (GO:0045178). The BP primarily involves ameboidal- type cell migration (GO:0001667), epidermis development (GO:0008544), epithelial cell proliferation (GO:0050673), and cell junction assembly (GO:0034329, Supplementary Table 5A). In addition, the main signaling pathways were identified by KEGG enrichment analysis, revealing that the over-expressed genes were primarily involved in the PI3K-Akt signaling pathway (hsa04151), focal adhesion (hsa04510), dilated cardiomyopathy (hsa05414), and small cell lung cancer (hsa05222, Figure 8 and Supplementary Table 5B).

\section{Gene set enrichment analyses}

Based on gene set enrichment analyses (GSEA), the majority of NRGs prognostic signature regulated immune and tumor-related pathways such as proteasome, steroid biosynthesis, pentose phosphate pathway, aminoacyl tRNA biosynthesis, p53, notch, and wnt signaling pathway. The top 6 enriched functions or pathways for each cluster are shown in Figure 9 and Supplementary Table 6A, 6B. Consequently, the "p53 signaling pathway" was the most enriched.

\section{Comparison of the immune activity among subgroups}

We evaluated the enrichment scores of 16 kinds of immune cells and the activity of 13 immune-related functions across low- and high-risk groups (ssGSEA). aDCs, DCs, iDCs, macrophages, Th2 cells, and Treg did not differ substantially between the two groups
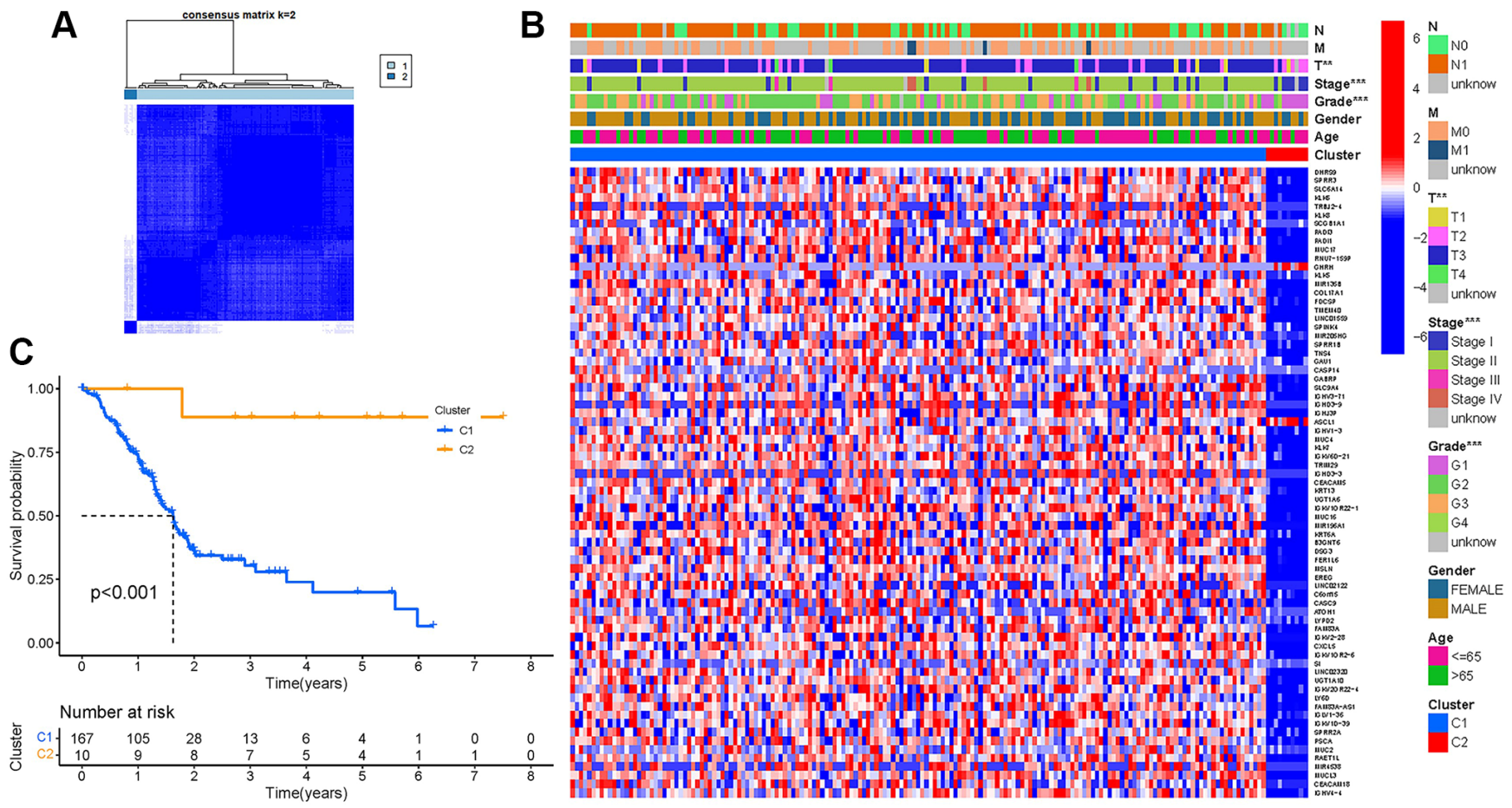

Figure 4. Tumor classification. (A) Consensus clustering matrix $(k=2)$. (B) Heatmap. (C) Kaplan-Meier OS curves. 
in the TCGA cohort $(P>0.05)$. Other immune cells infiltrate at a greater rate in the high-risk subgroup (Figure 10A). CCR, check point, HLA, inflammation-related promotion, and $\mathrm{T}$ cell coinhibition were not substantially different between the two groups $(P>0.05)$. Other immune-related functions are usually more significant in the highrisk group (Figure 10B). Similar findings were reached when examining the immunological state of the GEO cohort (Figure 10C, 10D).

\section{Analysis of the correlation among NRGs with immune checkpoints and m6A}

We investigated potential changes in immune checkpoint expression and m6A genes between the two groups. The expression of HHLA2, CD48, CD40LG, PDCD1, CD200, CD27, and other genes differed significantly between the two patient groups (Figure 11A). When the PRG expression was examined between the two-risk groups, METTL3, METTL14, HNRNPC, WTAP, YTHDC2, and ALKBH5 were substantially more significant in the high-risk group (Figure 11B). HNRNPC associated with m6A modification had higher expression in high risk group, suggesting that it might be related to the oncology process for PAAD patients. While METTL14, WTAP, METTL3, ALKBH5, and YTHDC2 had lower expression in high risk group, indicating that they might be tumor suppressor.

\section{DISCUSSION}

Treating PAAD is a severe clinical issue because of its advanced stages and terrible illness [20]. The molecular identification of diagnostic biomarkers and treatment
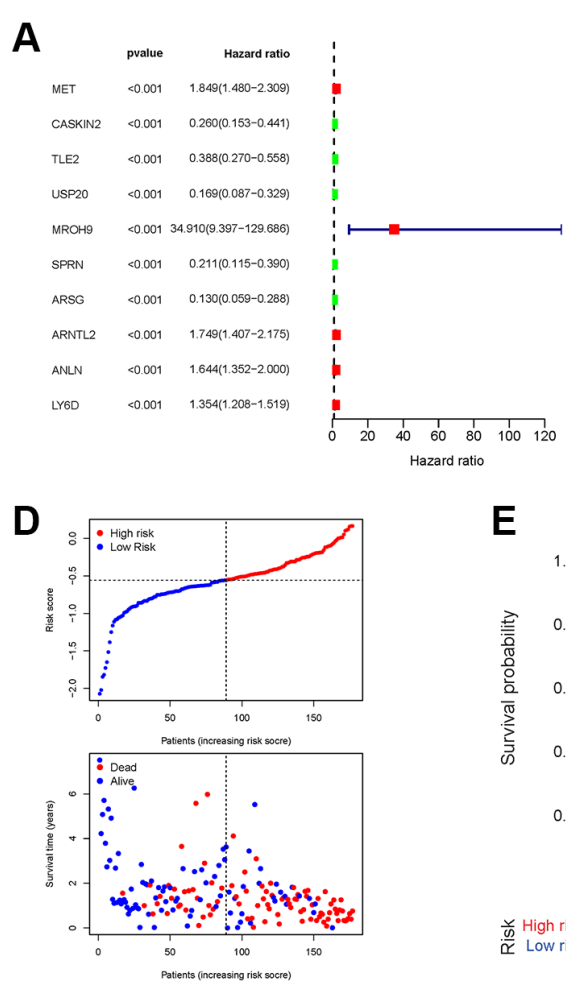

$\mathbf{E}$
B
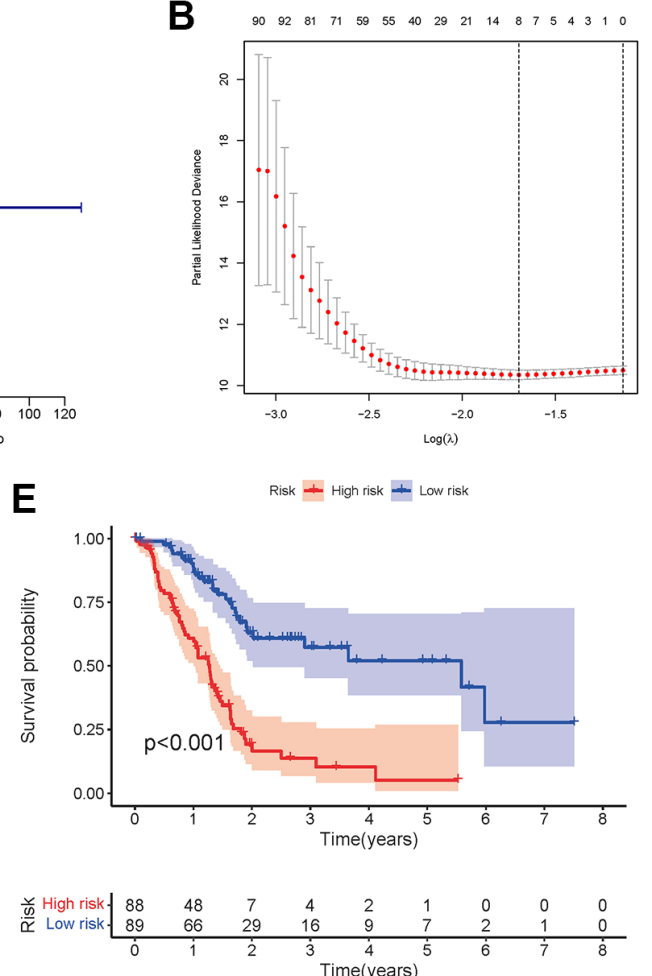

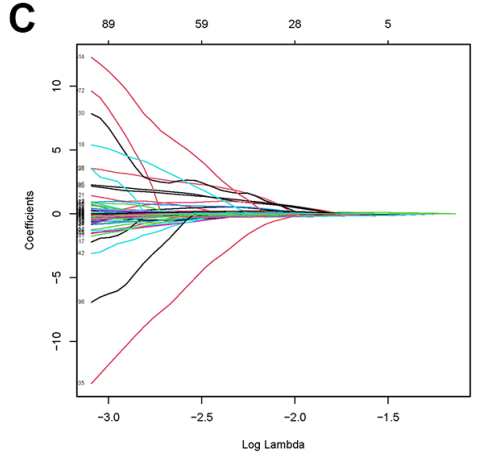

$\mathbf{F}$

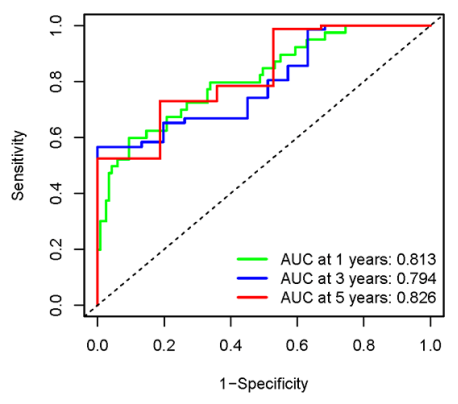

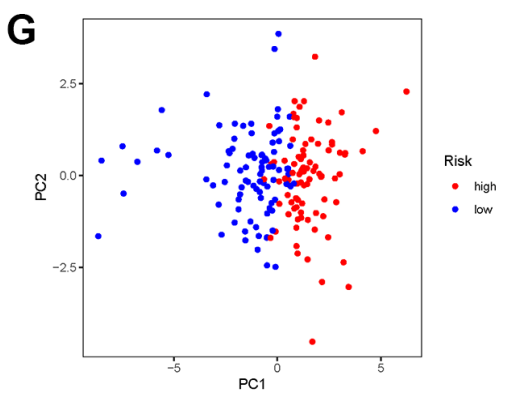

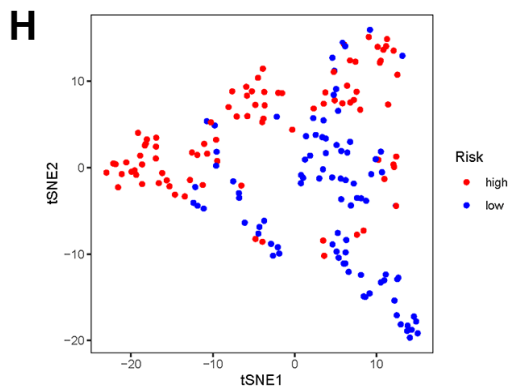

Figure 5. Construction of risk signature in the TCGA cohort. (A) Univariate cox regression analysis of OS. (B) LASSO regression of OSrelated genes. (C) Cross-validation for tuning the parameter selection. (D) Risk survival status plot. (E) Kaplan-Meier curve result. (F) The AUC of the prediction of 1, 3, 5-year survival rate of PAAD. (G) PCA plot. (H) t-SNE plot. 
targets for PAAD should always be prioritized. Previous research has shown that vanadium complexes have a selective cytotoxic effect on the human pancreatic ductal adenocarcinoma cell line (PANC-1), causing the mixture of apoptotic and necroptotic processes of PANC-1 cells at increasing doses [21]. Necroptotic programmed cell death is an alternate method of programmed cell death, which can address apoptosis resistance and activate and enhance antitumor immunity in cancer treatment [22]. Necroptosis can serve as a tumor suppressor, making it a potentially practical cancer therapy approach [23]. This research has been

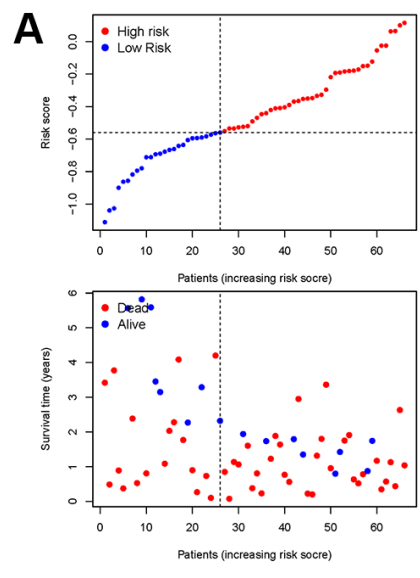

B
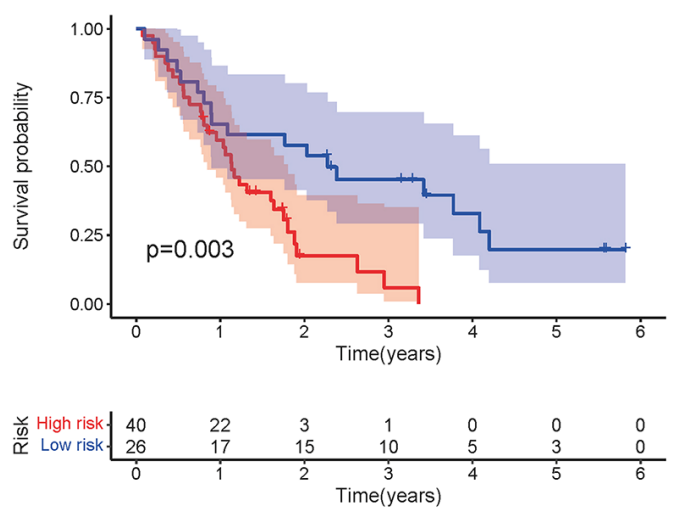

C

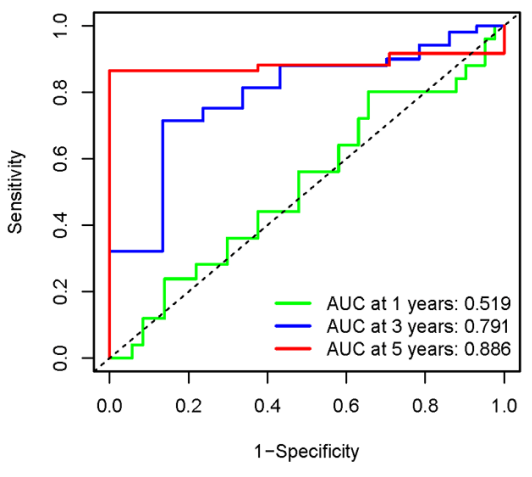

D

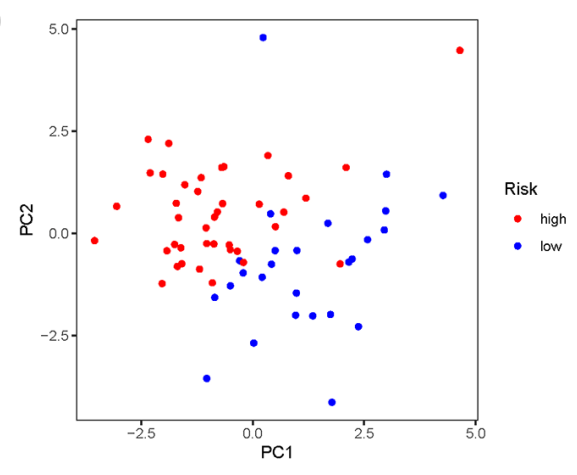

E

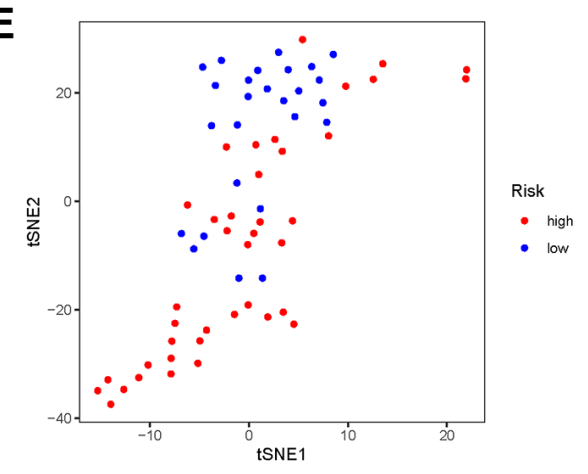

Figure 6. Validation of the risk model in the GEO cohort. (A) Risk survival status plot. (B) Kaplan-Meier curve result. (C) The AUC of the prediction of 1, 3, 5-year survival rate of PAAD. (D) PCA plot. (E) t-SNE plot.

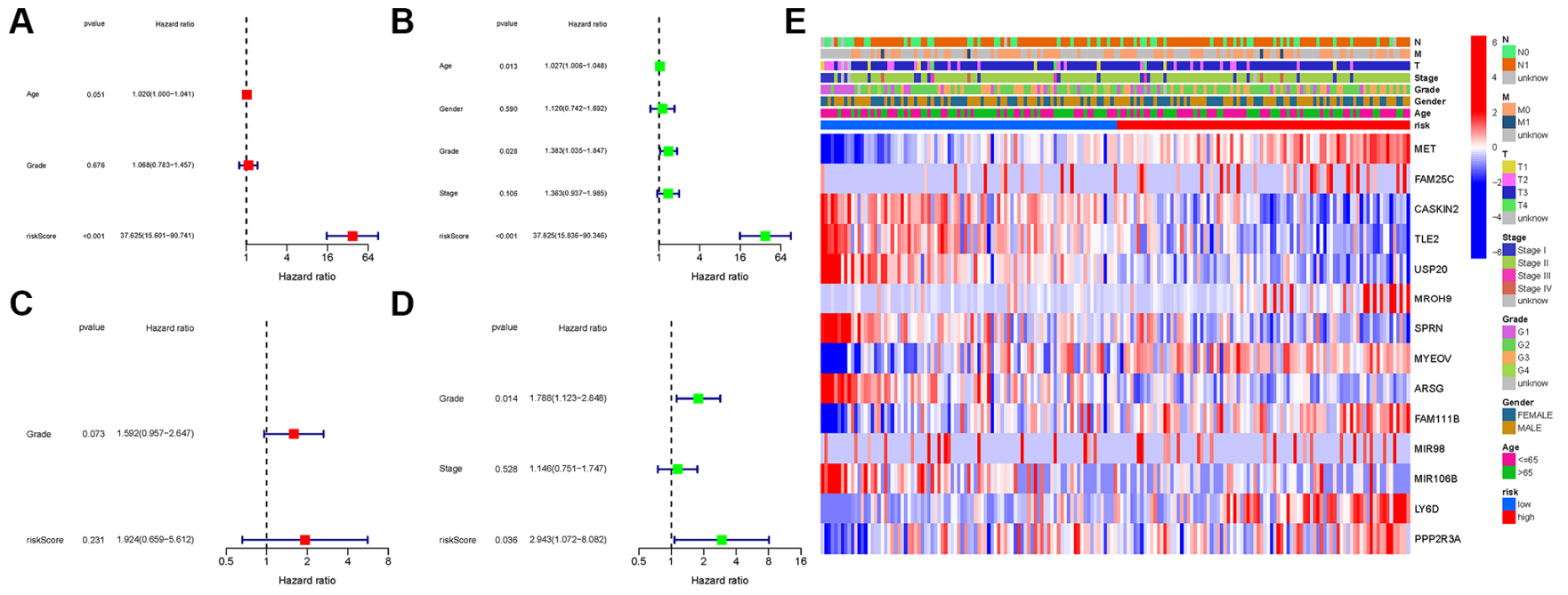

Figure 7. Univariate and multivariate cox regression analyses. (A, B) TCGA cohort. (C, D) GEO cohort. (A, C) Univariate analysis. (B, D) Multivariate analysis. (E) Heatmap. 
conducted to investigate the involvement of essential targets and pathways in PAAD prognosis, resulting in the identification of a feasible biomarker and therapy target.

We found 25 DEGs associated with necroptosis, and the genes were divided into two groups to investigate their possible involvement in PAAD. Based on previous studies, NRGs were significantly linked to PAAD prognosis in a university Cox regression study. The researchers found that 14 prognostic NRGs were expressed differently in risk individuals. Some NRGs were found to be overexpressed in high-risk individuals $(P<0.05)$. In addition, we investigated the role of NRGs in PAAD. A survival study was used to measure the predictive value of NRGs. Patients with low-risk NRGs had longer life span. MET, AM25C, MROH9, MYEOV, FAM111B, Y6D, and PPP2R3A were highly expressed in the high-risk group, indicating that these genes may be related to the oncology process for patients with PAAD, and they seemed to be cancerpromoting genes. The results of the abovementioned genes provide some insights for further research, but conclusive evidence that they are involved in the expression of specific transcription factors related to necroptosis regulation, such as USP22, CDK9, and Foxo1 [24-26] is lacking, which requires further investigation. CASKIN2, TLE2, USP20, SPRN, ARSG, MIR106B, and MIR98 were considered to be substantially expressed in the low-risk group, suggesting that these genes may be PAAD tumor suppressor genes.

DATE truncation activated HGF expression in CRC cell lines, resulting in autocrine signaling via MET, thereby increasing cell proliferation and resistance to necroptosis. HGF signaling via MET decreased the levels of receptor-interacting serine-threonine kinase 1, a necroptosis mediator, in CRC cells [27]. MYEOV promotes pancreatic cancer progression by increasing HES1 expression and SOX9 transactivity [28]. The FAM111B gene mutation is linked to inherited exocrine pancreatic dysfunction [29]. TLE2 is linked to a good prognosis in pancreatic cancer, which regulates cell growth and gemcitabine sensitivity. These studies also demonstrate the validity and credibility of our findings
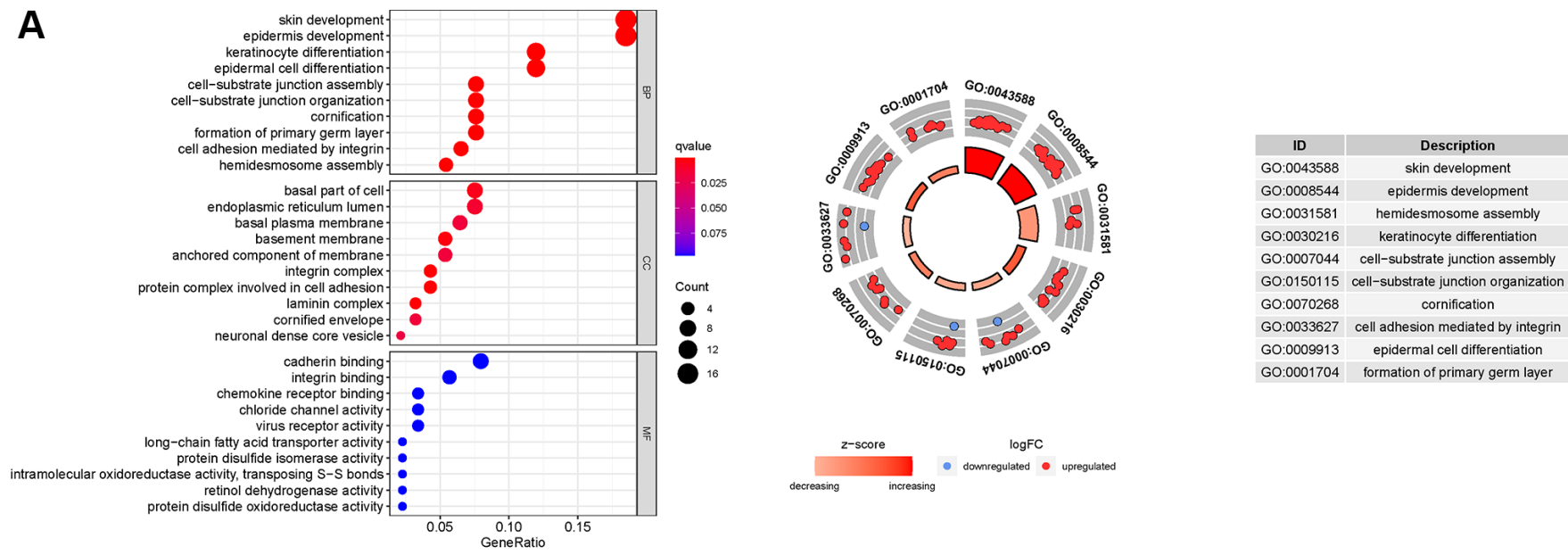

B
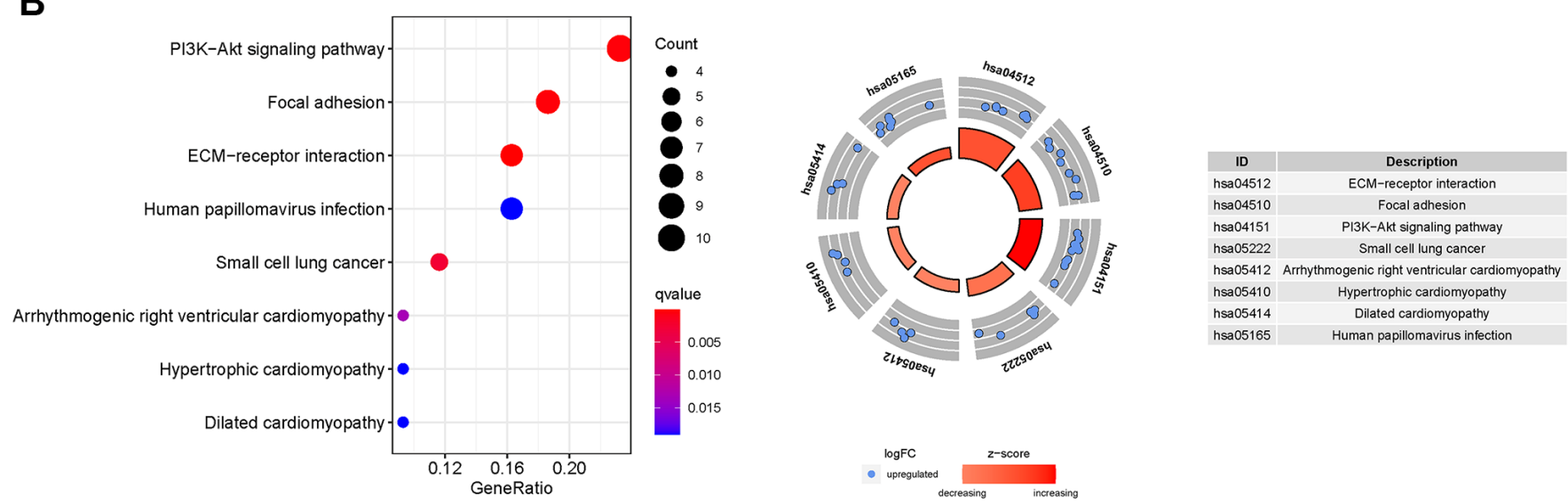

Figure 8. GO and KEGG analyses for ARGs. (A) GO, (B) KEGG. 
[30]. The OS based on GSE62452 Kaplan-Meier curves and ROC analyses revealed that a necroptosis-related signature might be an independent prognostic predictor.

Little research has been conducted on gene changes

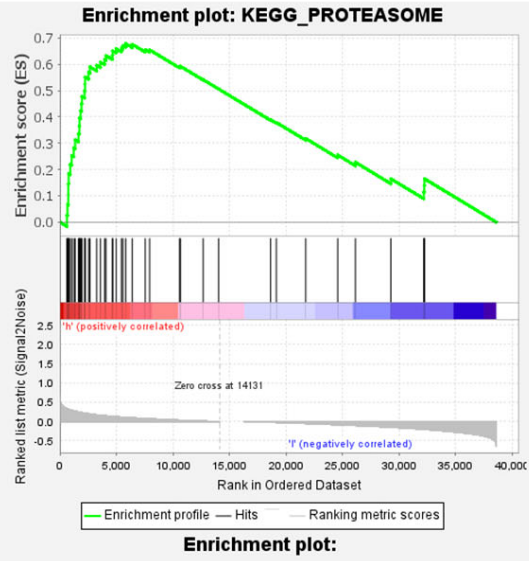

KEGG_AMINOACYL_TRNA_BIOSYNTHESIS

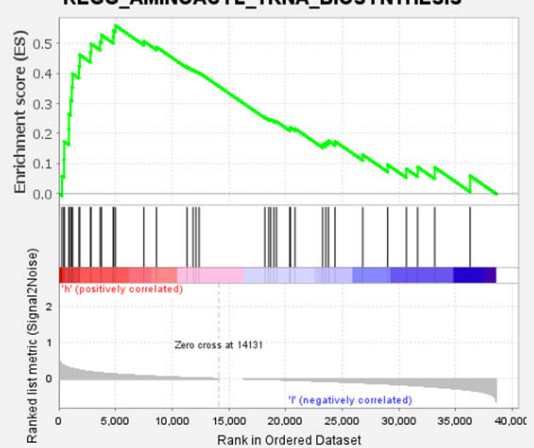

-Enrichment profile - Hits - Ranking metric scores

Enrichment plot: KEGG_PRIMARY_IMMUNODEFICIENCY

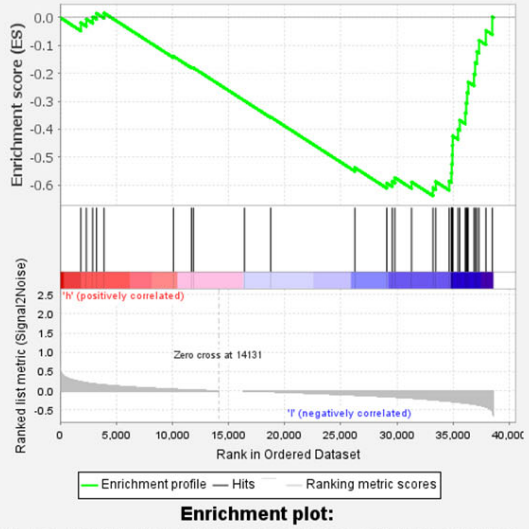

KEGG_MATURITY_ONSET_DIABETES_OF_THE_YOUNG

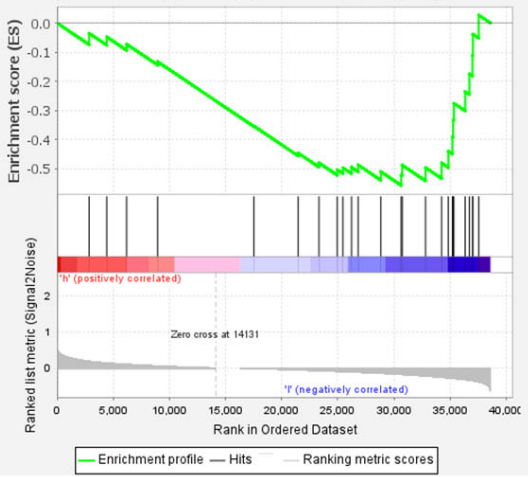

Enrichment plot: KEGG_STEROID_BIOSYNTHESIS

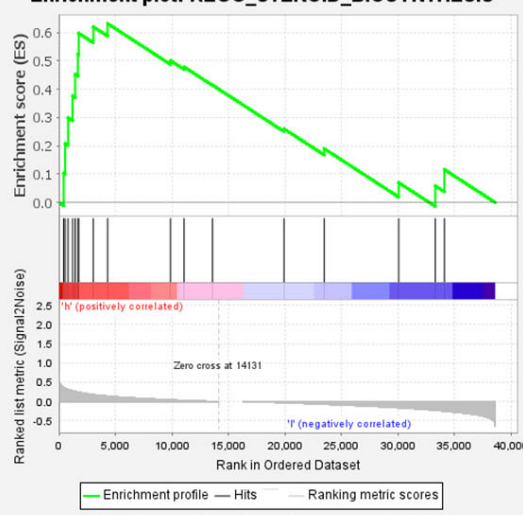

Enrichment plot: KEGG_THYROID_CANCER
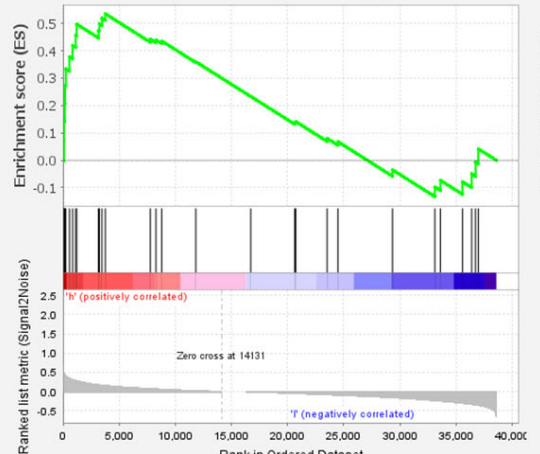

$\begin{array}{lllll}5.000 & 10.000 & 15.000 & 20.000 & 25.000\end{array}$

- Enrichment profle - Hits —Ranking metric scores

Enrichment plot: KEGG_ASTHMA

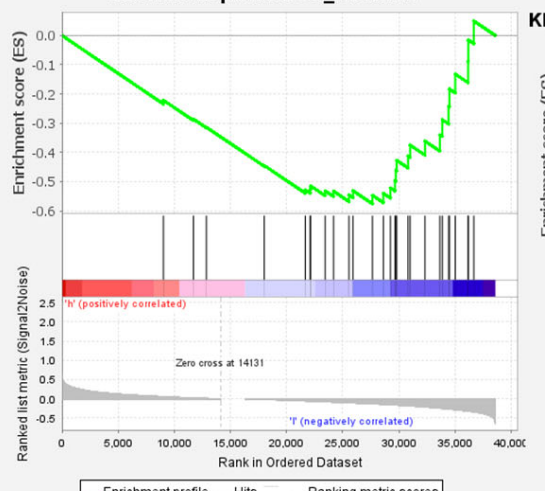

-Enrichment profile - Hilts - Ranking metric scores

Enrichment plot:

KEGG_HEMATOPOIETIC_CELL_LINEAGE

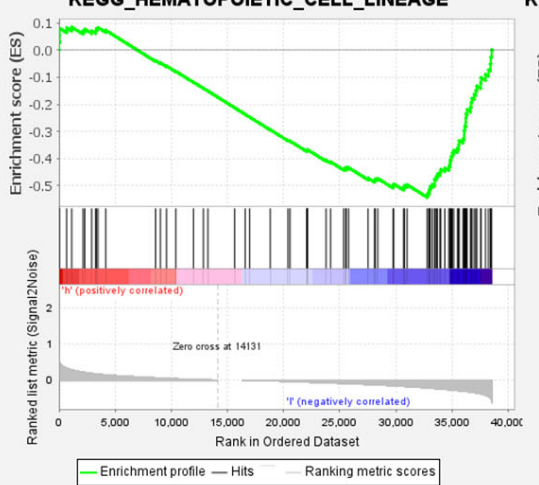

Enrichment plot:

KEGG_PENTOSE_PHOSPHATE_PATHWAY

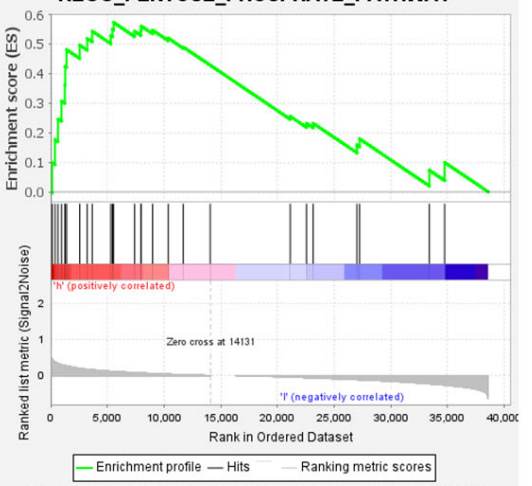

Enrichment plot: KEGG_BASE_EXCISION_REPAIR

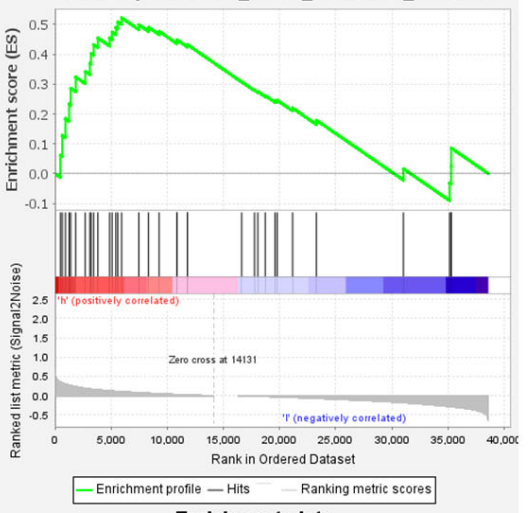

Enrichment plot:

KEGG_INTESTINAL_IMMUNE_NETWORK_FOR_IGA_PRO DUCTION

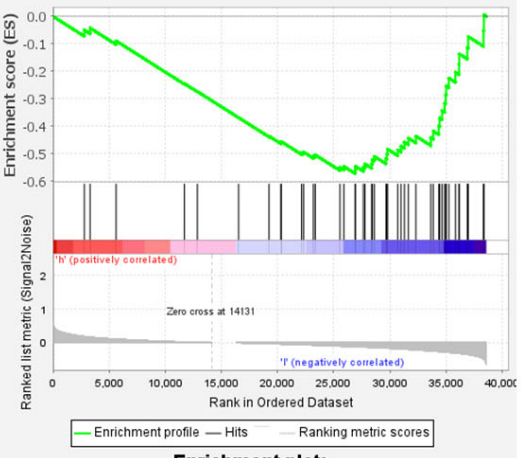

KEGG_GLYCOSPHINGOLIPID_BIOSYNTHESIS_GANGLIO _SERIES

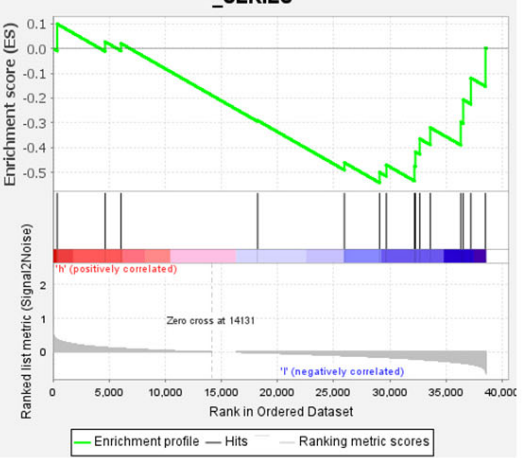

Figure 9. Gene set enrichment analyses. 
A

Risk 追 low 追 high

B

Risk 追 low 追 high
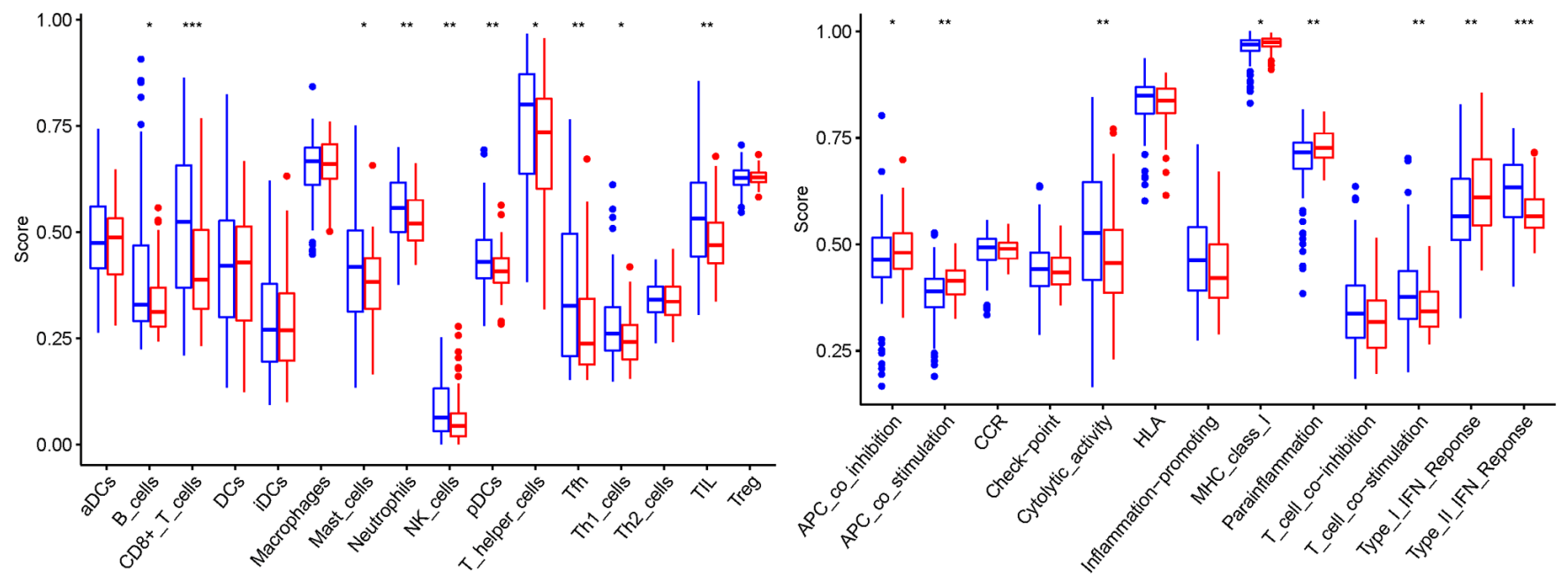

C
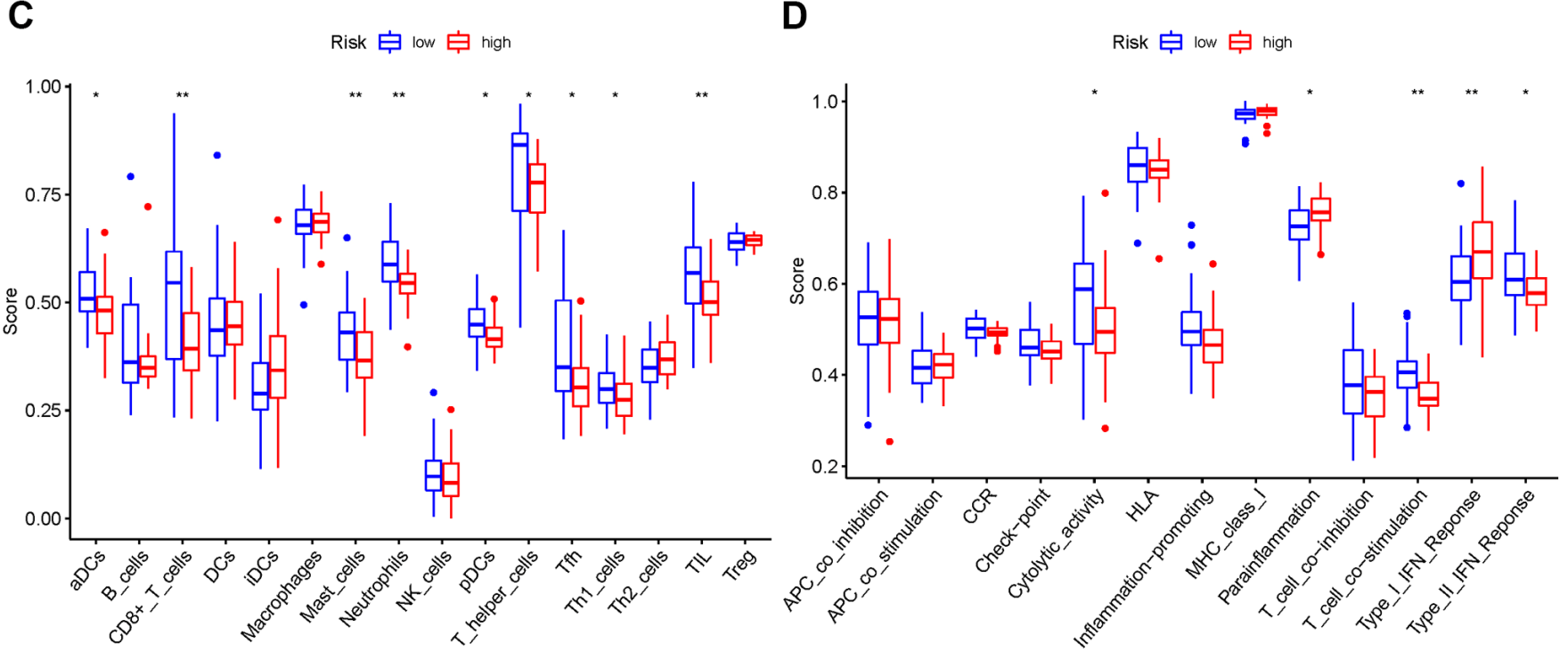

Figure 10. Comparison among ssGSEA scores. (A, B) TCGA cohort, (C, D) GEO cohort.
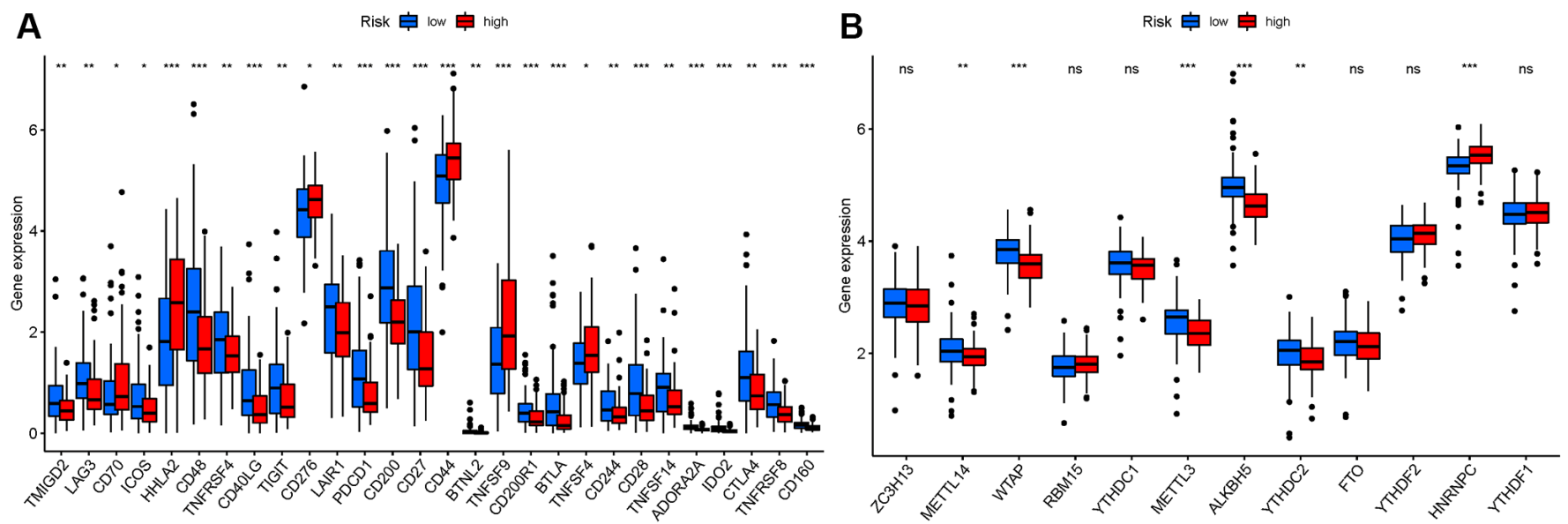

Figure 11. Analysis of the correlation of NRGs. (A) ICRGs in PAAD risk groups. (B) M6A-NRG in PAAD risk groups. 
linked with necroptosis. Therefore, more research is needed to comprehend the mechanism of NRG change and fully identify and corroborate our findings.

In addition, KEGG analysis showed that NRGs were primarily involved in the PI3K-Akt signaling pathway. PI3K enhances tumor necrosis factor-induced necroptosis by activating the RIP1-RIP3-MLKL signaling pathway [31]. Consequently, necroptosis is crucial in PAAD. In GSEA, the p53 signaling pathway was the most significantly enriched pathway. A recent study has shown that p53 not only can cause necrosis via opening the mitochondrial permeability transition pore, but also can interact directly with cyclophilin D (CypD) to open the permeability transition pore (PTP) in the oxidative stress response [32]. In vitro and in vivo research has revealed that cyclin-dependent kinase inhibitor 3 (CDKN3) is adversely associated with pancreatic cancer tissue prognosis. CDKN3 can form a complex with MDM2-p53 to suppress the production of the P53 target gene P21, promoting the cell cycle and proliferation of PADD cells [33]. Considering the abovementioned criteria, NRGs may influence PAAD cell migration and proliferation via modulating the P53 signaling pathway.

Our method successfully predicts the survival of patients with PAAD. Based on the NRGs prognostic model, a rise in the risk score is associated with an increase in death and high-risk ratio. NRGs may be important biomarkers for predicting outcomes of patients with PAAD. Furthermore, we investigated and studied the relationship among NRGs, immune cells, immunological activity, immune checkpoints, and m6A. Recent research has found a link between various cell death mechanisms and antitumor immunity. Even in ICI-resistant tumors, pyroptosis, ferroptosis, and necroptosis activation combined with ICIs resulted in synergistically increased anticancer efficacy [34, 35]. An immunological checkpoint is the connection between SLC41A3 expression and immune cell invasion [36]. A microscopic investigation of the relationship among ICI, m6A, and pyrolysis has been conducted. Despite little analysis performed on NRGs and PAAD, supported by the abovementioned information, NRGs alterations were associated with the onset and development of PAAD.

Our research has limitations, although it is provided for theoretical underpinnings and research suggestions. First, we were unable to acquire sufficient external data from other publicly available sources to evaluate model's dependability. Second, we focused on signature of 14 risk-NRGs in our early expression study. However, no further functional or mechanistic research was conducted. Finally, no PAAD studies were conducted to confirm the link between prognostic genes and pyrolysis. Therefore, further research must be conducted to confirm the abovementioned findings.

\section{CONCLUSIONS}

A total of 14 anticipated NRGs were identified in patients with PAAD. The findings contributed to the comprehensive understanding of the relationship among necroptosis, immunological function, ICI, m6A, and immune cells, understanding the potential role of NRGs in the generation and development of PAAD malignant tumors, to provide research ideas for finding new therapeutic targets and prognostic indicators.

\section{Abbreviations}

PAAD: Pancreatic adenocarcinoma; GO: Gene ontology; AUC: Areas under the curve; MF: Molecular functions; ICIs: Immune checkpoint inhibitors; ROC: Receiver-operating characteristics; GSEA: Gene set enrichment analyses; TCGA: The Cancer Genome Atlas; NRGs: Necroptosis-related genes; BP: Biological processes; CC: Cellular components; OS: Overall survival; GEO: Gene Expression Omnibus; DEGs: Differentially expressed genes; KEGG: Kyoto Encyclopedia of Genes and Genomes.

\section{AUTHOR CONTRIBUTIONS}

Zixuan $\mathrm{Wu}$ drafted and revised the manuscript. Xuyan Huang and Minjie Cai were in charge of data collection. Peidong Huang conceived and designed this article, in charge of syntax modification, and revised the manuscript. Zunhui Guan revised the manuscript. All the authors have read and agreed to the final version of the manuscript.

\section{ACKNOWLEDGMENTS}

Thanks to Professor Huang for his strict guidance on this paper, and thanks to Miss Huang and Miss Cai for their support to this paper. Thanks to reviewers and editors for their sincere comments.

\section{CONFLICTS OF INTEREST}

The authors declare no conflicts of interest related to this study.

\section{FUNDING}

Health and Health Commission of Yunnan Province 2020 High-level TCM Reserve Talents Incubation Project (Yunwei TCM Development [2021] No. 1). The second round of construction project of The National Traditional 
Chinese Medicine School Heritage Studio of the State Administration of Traditional Chinese Medicine (National Traditional Chinese Medicine Teaching Letter [2019] 62). Scientific and Technological Innovation Team of Acupuncture and Moxibustion Prevention and Treatment of Mental Disorders in Yunnan Colleges and Universities (No.: 2019YGC04).

\section{REFERENCES}

1. Katona BW, Brand RE, Canto MI, Chak A, Farrell JJ, Kastrinos F, Rustgi AK, Stoffel EM, Syngal S, Goggins $M$, and CAPS5 Study Consortium. Screening for Pancreatic Ductal Adenocarcinoma: Are We Asking the Impossible?-Letter. Cancer Prev Res (Phila). 2021; 14:973-4.

https://doi.org/10.1158/1940-6207.CAPR-21-0233 PMID:34607877

2. Pasqualetti F, Sainato A, Morganti R, Laliscia C, Vasile E, Gonnelli A, Montrone S, Gadducci G, Giannini N, Coccia N, Fuentes T, Zanotti S, Falconi M, Paiar F. Adjuvant Radiotherapy in Patients With Pancreatic Adenocarcinoma. Is It Still Appealing in Clinical Trials? A Meta-analysis and Review of the Literature. Anticancer Res. 2021; 41:4697-704.

https://doi.org/10.21873/anticanres.15283 PMID: $\underline{34593417}$

3. Jin $G$, Ruan $Q$, Shangguan F, Lan L. RUNX2 and LAMC2: promising pancreatic cancer biomarkers identified by an integrative data mining of pancreatic adenocarcinoma tissues. Aging (Albany NY). 2021; 13:22963-84. https://doi.org/10.18632/aging.203589 PMID:34606473

4. Sordo-Bahamonde C, Lorenzo-Herrero S, Payer ÁR, Gonzalez S, López-Soto A. Mechanisms of Apoptosis Resistance to NK Cell-Mediated Cytotoxicity in Cancer. Int J Mol Sci. 2020; 21:3726. https://doi.org/10.3390/ijms21103726 PMID: $\underline{32466293}$

5. Zhang P, Kawakami H, Liu W, Zeng X, Strebhardt K, Tao K, Huang S, Sinicrope FA. Targeting CDK1 and MEK/ERK Overcomes Apoptotic Resistance in BRAFMutant Human Colorectal Cancer. Mol Cancer Res. 2018; 16:378-89.

https://doi.org/10.1158/1541-7786.MCR-17-0404 PMID:29233910

6. Chan VSH, Lam TPW, Lam WWM. Nephroptosis: The wandering kidney. Kidney Res Clin Pract. 2018; 37:306-7.

https://doi.org/10.23876/i.krcp.2018.37.3.306 PMID:30254857

7. Degterev A, Hitomi J, Germscheid M, Ch'en IL, Korkina O, Teng X, Abbott D, Cuny GD, Yuan C, Wagner G,
Hedrick SM, Gerber SA, Lugovskoy A, Yuan J. Identification of RIP1 kinase as a specific cellular target of necrostatins. Nat Chem Biol. 2008; 4:313-21.

https://doi.org/10.1038/nchembio.83

PMID:18408713

8. Feng $X$, Song $Q, Y u A$, Tang $H$, Peng $Z$, Wang $X$. Receptor-interacting protein kinase 3 is a predictor of survival and plays a tumor suppressive role in colorectal cancer. Neoplasma. 2015; 62:592-601.

https://doi.org/10.4149/neo 2015071 PMID:25997957

9. Höckendorf U, Yabal M, Herold T, Munkhbaatar E, Rott S, Jilg S, Kauschinger J, Magnani G, Reisinger F, Heuser M, Kreipe H, Sotlar K, Engleitner T, et al. RIPK3 Restricts Myeloid Leukemogenesis by Promoting Cell Death and Differentiation of Leukemia Initiating Cells. Cancer Cell. 2016; 30:75-91.

https://doi.org/10.1016/i.ccell.2016.06.002 PMID:27411587

10. Seifert L, Werba G, Tiwari S, Giao Ly NN, Alothman S, Alqunaibit D, Avanzi A, Barilla R, Daley D, Greco SH, Torres-Hernandez A, Pergamo M, Ochi A, et al. The necrosome promotes pancreatic oncogenesis via CXCL1 and Mincle-induced immune suppression. Nature. 2016; 532:245-9.

https://doi.org/10.1038/nature17403

PMID:27049944

11. Krysko O, Aaes TL, Kagan VE, D'Herde K, Bachert C, Leybaert L, Vandenabeele P, Krysko DV. Necroptotic cell death in anti-cancer therapy. Immunol Rev. 2017; 280:207-19.

https://doi.org/10.1111/imr.12583

PMID:29027225

12. Yan J, Wan P, Choksi S, Liu ZG. Necroptosis and tumor progression. Trends Cancer. 2022; 8:21-7. https://doi.org/10.1016/i.trecan.2021.09.003 PMID: 34627742

13. Zhao E, Chen S, Dang Y. Development and External Validation of a Novel Immune Checkpoint-Related Gene Signature for Prediction of Overall Survival in Hepatocellular Carcinoma. Front Mol Biosci. 2021; 7:620765.

https://doi.org/10.3389/fmolb.2020.620765 PMID:33553243

14. Ye Y, Dai Q, Qi H. A novel defined pyroptosis-related gene signature for predicting the prognosis of ovarian cancer. Cell Death Discov. 2021; 7:71. https://doi.org/10.1038/s41420-021-00451-x PMID:33828074

15. Wang Z, Jensen MA, Zenklusen JC. A Practical Guide to The Cancer Genome Atlas (TCGA). Methods Mol Biol. 2016; 1418:111-41. 
https://doi.org/10.1007/978-1-4939-3578-9 6 PMID:27008012

16. Yu ZL, Zhu ZM. Comprehensive analysis of N6methyladenosine -related long non-coding RNAs and immune cell infiltration in hepatocellular carcinoma. Bioengineered. 2021; 12:1708-24. https://doi.org/10.1080/21655979.2021.1923381 PMID:33955330

17. Wu P, Heins ZJ, Muller JT, Katsnelson L, de Bruijn I, Abeshouse AA, Schultz N, Fenyö D, Gao J. Integration and Analysis of CPTAC Proteomics Data in the Context of Cancer Genomics in the cBioPortal. Mol Cell Proteomics. 2019; 18:1893-8.

https://doi.org/10.1074/mcp.TIR119.001673 PMID: $\underline{31308250}$

18. David CC, Jacobs DJ. Principal component analysis: a method for determining the essential dynamics of proteins. Methods Mol Biol. 2014; 1084:193-226. https://doi.org/10.1007/978-1-62703-658-0 11 PMID:24061923

19. Tang Y, Li C, Zhang YJ, Wu ZH. Ferroptosis-Related Long Non-Coding RNA signature predicts the prognosis of Head and neck squamous cell carcinoma. Int J Biol Sci. 2021; 17:702-11.

https://doi.org/10.7150/ijbs.55552 PMID: $\underline{3767582}$

20. Lambert A, Schwarz L, Ducreux M, Conroy T. Neoadjuvant Treatment Strategies in Resectable Pancreatic Cancer. Cancers (Basel). 2021; 13:4724.

https://doi.org/10.3390/cancers13184724 PMID:34572951

21. Kowalski S, Hać S, Wyrzykowski D, ZauszkiewiczPawlak A, Inkielewicz-Stępniak I. Selective cytotoxicity of vanadium complexes on human pancreatic ductal adenocarcinoma cell line by inducing necroptosis, apoptosis and mitotic catastrophe process. Oncotarget. 2017; 8:60324-41.

https://doi.org/10.18632/oncotarget.19454 PMID:28947974

22. Erkes DA, Cai W, Sanchez IM, Purwin TJ, Rogers C, Field CO, Berger AC, Hartsough EJ, Rodeck U, Alnemri ES, Aplin AE. Mutant BRAF and MEK Inhibitors Regulate the Tumor Immune Microenvironment via Pyroptosis. Cancer Discov. 2020; 10:254-69. https://doi.org/10.1158/2159-8290.CD-19-0672 PMID:31796433

23. Hou J, Zhao R, Xia W, Chang CW, You Y, Hsu JM, Nie L, Chen Y, Wang YC, Liu C, Wang WJ, Wu Y, Ke B, et al. Author Correction: PD-L1-mediated gasdermin C expression switches apoptosis to pyroptosis in cancer cells and facilitates tumour necrosis. Nat Cell Biol. 2020; 22:1396. https://doi.org/10.1038/s41556-020-00599-1 PMID:33033376

24. Roedig J, Kowald L, Juretschke T, Karlowitz R, Ahangarian Abhari B, Roedig H, Fulda S, Beli P, van Wijk SJ. USP22 controls necroptosis by regulating receptor-interacting protein kinase 3 ubiquitination. EMBO Rep. 2021; 22:e50163. https://doi.org/10.15252/embr.202050163 PMID:33369872

25. Li J, Shi J, Pan Y, Zhao Y, Yan F, Li H, Lei L. Transcription modulation by CDK9 regulates inflammatory genes and RIPK3-MLKL-mediated necroptosis in periodontitis progression. Sci Rep. 2019; 9:17369.

https://doi.org/10.1038/s41598-019-53910-y PMID: 31758083

26. Li C, Sheng $M$, Lin $Y, X u D$, Tian $Y$, Zhan $Y$, Jiang $L$, Coito AJ, Busuttil RW, Farmer DG, Kupiec-Weglinski JW, Ke B. Functional crosstalk between myeloid Foxo1- $\beta$-catenin axis and Hedgehog/Gli1 signaling in oxidative stress response. Cell Death Differ. 2021; 28:1705-19. https://doi.org/10.1038/s41418-020-00695-7 PMID:33288903

27. Seneviratne D, Ma J, Tan X, Kwon YK, Muhammad E, Melhem M, DeFrances MC, Zarnegar R. Genomic instability causes HGF gene activation in colon cancer cells, promoting their resistance to necroptosis. Gastroenterology. 2015; 148:181-91.e17. https://doi.org/10.1053/i.gastro.2014.09.019 PMID:25244939

28. Liang E, Lu Y, Shi Y, Zhou Q, Zhi F. MYEOV increases HES1 expression and promotes pancreatic cancer progression by enhancing SOX9 transactivity. Oncogene. 2020; 39:6437-50.

https://doi.org/10.1038/s41388-020-01443-4 PMID: $\underline{32879444}$

29. Seo A, Walsh T, Lee MK, Ho PA, Hsu EK, Sidbury R, King MC, Shimamura A. FAM111B Mutation Is Associated With Inherited Exocrine Pancreatic Dysfunction. Pancreas. 2016; 45:858-62. https://doi.org/10.1097/MPA.0000000000000529 PMID:26495788

30. Hu S, Chen Z, Gu J, Tan L, Zhang M, Lin W. TLE2 is associated with favorable prognosis and regulates cell growth and gemcitabine sensitivity in pancreatic cancer. Ann Transl Med. 2020; 8:1017. https://doi.org/10.21037/atm-20-5492 PMID:32953817

31. Hu S, Chang X, Zhu H, Wang D, Chen G. PI3K mediates tumor necrosis factor induced-necroptosis through initiating RIP1-RIP3-MLKL signaling pathway activation. Cytokine. 2020; 129:155046. 
https://doi.org/10.1016/j.cyto.2020.155046

PMID: $\underline{32114297}$

32. Garancher A, Suzuki H, Haricharan S, Chau LQ, Masihi MB, Rusert JM, Norris PS, Carrette F, Romero MM, Morrissy SA, Skowron P, Cavalli FMG, Farooq H, et al. Tumor necrosis factor overcomes immune evasion in p53-mutant medulloblastoma. Nat Neurosci. 2020; 23:842-53.

https://doi.org/10.1038/s41593-020-0628-4

PMID:32424282 Retraction in: Nat Neurosci. 2022; 25:127.

https://doi.org/10.1038/s41593-021-00994-3 PMID:34907396

33. Liu D, Zhang J, Wu Y, Shi G, Yuan H, Lu Z, Zhu Q, Wu P, Lu C, Guo F, Chen J, Jiang K, Miao Y. YY1 suppresses proliferation and migration of pancreatic ductal adenocarcinoma by regulating the CDKN3/MdM2/P53/P21 signaling pathway. Int J Cancer. 2018; 142:1392-404.

https://doi.org/10.1002/ijc.31173

PMID:29168185
34. Tang $\mathrm{R}$, Xu J, Zhang B, Liu J, Liang $\mathrm{C}$, Hua J, Meng $\mathrm{Q}$, Yu $X$, Shi S. Ferroptosis, necroptosis, and pyroptosis in anticancer immunity. J Hematol Oncol. 2020; 13:110. https://doi.org/10.1186/s13045-020-00946-7 PMID:32778143

35. Hsu SK, Li CY, Lin IL, Syue WJ, Chen YF, Cheng KC, Teng YN, Lin $\mathrm{YH}$, Yen $\mathrm{CH}$, Chiu CC. Inflammationrelated pyroptosis, a novel programmed cell death pathway, and its crosstalk with immune therapy in cancer treatment. Theranostics. 2021; 11:8813-35.

https://doi.org/10.7150/thno.62521

PMID:34522213

36. Liu J, Zhang S, Dai W, Xie C, Li JC. A Comprehensive Prognostic and Immune Analysis of SLC41A3 in PanCancer. Front Oncol. 2021; 10:586414. https://doi.org/10.3389/fonc.2020.586414 PMID:33520701 


\section{SUPPLEMENTARY MATERIALS}

\section{Supplementary Tables}

Supplementary Table 1.52 necroptosis-related genes.

\begin{tabular}{lllll}
\hline BAK1 & CHMP4B & IL18 & CASP9 & NLRP6 \\
BAX & CHMP4C & IL1A & GPX4 & NLRP7 \\
CASP1 & CHMP6 & IL1B & GSDMA & NOD1 \\
CASP3 & CHMP7 & IRF1 & GSDMB & NOD2 \\
CASP4 & CYCS & IRF2 & GSDMC & PJVK \\
CASP5 & ELANE & TP53 & IL6 & PLCG1 \\
CHMP2A & GSDMD & TP63 & NLRC4 & PRKACA \\
CHMP2B & GSDME & AIM2 & NLRP1 & PYCARD \\
CHMP3 & GZMB & CASP6 & NLRP2 & SCAF11 \\
CHMP4A & HMGB1 & CASP8 & NLRP3 & TIRAP \\
TNF & GZMA & & & \\
\hline
\end{tabular}

Supplementary Table 2. 25 DEGs linked to NRGs.

\begin{tabular}{lcccc}
\hline gene & conMean & treatMean & logFC & $\boldsymbol{p}$ Value \\
\hline TNF & 2.9597148 & 0.878954778 & -1.751597318 & 0.023229673 \\
CYBB & 44.8476025 & 13.38835502 & -1.74405215 & 0.004999667 \\
SLC25A6 & 260.2667 & 212.1314808 & -0.295032001 & 0.029730049 \\
PYGB & 26.3985825 & 75.0233836 & 1.506879866 & 0.002884394 \\
PLA2G4C & 3.36357325 & 1.527573251 & -1.138753114 & 0.007311847 \\
PLA2G4F & 0.096944548 & 0.69805447 & 2.848107951 & 0.01144699 \\
CAPN2 & 29.2810825 & 50.60433046 & 0.789291959 & 0.012420784 \\
NLRP3 & 2.307436 & 1.149735351 & -1.004988816 & 0.014207465 \\
RNF103-CHMP3 & 0.03308378 & 0.125159531 & 1.919572176 & 0.049686083 \\
CHMP4C & 7.25279525 & 14.30096114 & 0.979503084 & 0.038630253 \\
FASLG & 1.15240325 & 0.348416184 & -1.725762088 & 0.037736936 \\
IFNA2 & 0.012599015 & 0.001135769 & -3.471569966 & 0.000288726 \\
IFNA6 & 0.021787193 & 0.001020912 & -4.415549216 & 0.000203649 \\
IFNA13 & 0.00733201 & 0.001187969 & -2.625711059 & 0.001901453 \\
IFNGR1 & 67.564385 & 40.74547212 & -0.729623216 & 0.009433631 \\
JAK1 & 49.8170925 & 34.40897001 & -0.533856116 & 0.044375834 \\
JAK3 & 12.6223675 & 4.252687198 & -1.569535885 & 0.019953735 \\
TYK2 & 19.87963 & 12.60590665 & -0.657191021 & 0.048594059 \\
STAT4 & 3.619687 & 1.434699334 & -1.335116524 & 0.03600294 \\
STAT5A & 14.5681125 & 9.021417197 & -0.691387976 & 0.017539418 \\
TLR4 & 7.0368955 & 3.415832457 & -1.042701875 & 0.021537533 \\
TNFAIP3 & 30.580245 & 13.05847187 & -1.227613886 & 0.002033049 \\
H2AW & 3.70185 & 10.686664761 & 1.529491009 & 0.024420867 \\
H2AC6 & 10.024392 & 27.38610677 & 1.449929449 & 0.015385115 \\
BCL2 & 7.155259 & 2.040894169 & -1.809802617 & 0.014983353 \\
\hline
\end{tabular}


Supplementary Table 3. Hub genes.

\begin{tabular}{lcccc}
\hline Name & Betweenness & Closeness & Degree & Network \\
\hline JAK1 & 58.62251082 & 0.296875 & 11 & 9.223809524 \\
TNF & 30.05974026 & 0.287878788 & 11 & 9.555555556 \\
JAK3 & 42.26688312 & 0.292307692 & 10 & 8.103174603 \\
IFNGR1 & 20.94393939 & 0.28358209 & 10 & 8.158730159 \\
TLR4 & 32.18744589 & 0.28358209 & 10 & 8.357142857 \\
TYK2 & 13.49307359 & 0.28358209 & 10 & 8.583333333 \\
STAT4 & 5.093073593 & 0.275362319 & 8 & 6.726190476 \\
STAT5A & 13.33333333 & 0.271428571 & 7 & 5.833333333 \\
IFNA2 & 0.6 & 0.263888889 & 5.8 \\
IFNA6 & 0 & 0.256756757 & 5 & 5 \\
TNFAIP3 & 1.533333333 & 0.25 & 5 & 4.166666667 \\
CYBB & 1.2 & 0.25 & 5 & 3.333333333 \\
NLRP3 & 0.666666667 & 0.243589744 & 4 & 3.333333333 \\
BCL2 & 60 & 0.2533333333 & 4 & 1 \\
IFNA13 & 0 & 0.246753247 & 3 & 3 \\
HIST1H2AC & 32 & 0.213483146 & 3 & 0 \\
FASLG & 0 & 0.234567901 & 2 & 2 \\
CHMP3 & 0 & 0.052631579 & 2 & 0 \\
CHMP4C & 0 & 0.052631579 & 1 & 0 \\
HIST3H2A & 0 & 0.180952381 & 1 & 0 \\
\hline
\end{tabular}

Supplementary Table 4. 14 risk PRGs.

\begin{tabular}{lcccc}
\hline Id & TCGA-3A-A9J0 & TCGA-2L-AAQL & TCGA-US-A77E & TCGA-RB-AA9M \\
\hline MET & 5.042611 & 4.7215981 & 5.9641271 & 5.2955498 \\
FAM25C & 2.0205815 & 2.2528105 & 2.0205815 & 2.0205815 \\
CASKIN2 & 4.1749081 & 3.58593 & 4.0714195 & 4.1428019 \\
TLE2 & 4.1259097 & 4.624045 & 3.999072 & 4.7286858 \\
USP20 & 3.0161423 & 3.715024 & 3.7000295 & 3.641327 \\
MROH9 & 1.0486983 & 0.9140702 & 0.9140702 & 0.9350862 \\
SPRN & 2.6244162 & 2.8517601 & 2.3841645 & 2.6025939 \\
MYEOV & 3.2386553 & 4.1509198 & 4.4052511 & 3.667548 \\
ARSG & 2.2785722 & 2.0642247 & 2.3422646 & 2.3341557 \\
FAM111B & 2.6997762 & 1.4177758 & 1.9956956 & 2.4969894 \\
MIR98 & 0.8402696 & 1.218496 & 1.1183522 & 0.8402696 \\
MIR106B & 2.7306465 & 1.4784037 & 1.4784037 & 2.6675028 \\
LY6D & 1.9197985 & 2.4401492 & 2.8759444 & 5.8630146 \\
PPP2R3A & 2.3522622 & 2.2616753 & 2.9258627 & 3.446074 \\
riskScore & -0.847267824 & -0.659885519 & -0.580465013 & -0.643074732 \\
risk & low & low & low & low \\
\hline
\end{tabular}


Supplementary Table 5A. GO enrichment analysis.

\begin{tabular}{|c|c|c|c|c|}
\hline Ontology & Description & BgRatio & $p$ value & $q$ value \\
\hline BP & skin development & $415 / 18862$ & $1.49 \mathrm{E}-11$ & $2.35 \mathrm{E}-08$ \\
\hline $\mathrm{BP}$ & epidermis development & $463 / 18862$ & $8.27 \mathrm{E}-11$ & $6.50 \mathrm{E}-08$ \\
\hline BP & hemidesmosome assembly & $12 / 18862$ & $1.91 \mathrm{E}-09$ & $9.99 \mathrm{E}-07$ \\
\hline BP & keratinocyte differentiation & $302 / 18862$ & $2.51 \mathrm{E}-07$ & $9.88 \mathrm{E}-05$ \\
\hline BP & cell-substrate junction assembly & $100 / 18862$ & $5.77 \mathrm{E}-07$ & 0.000181471 \\
\hline $\mathrm{BP}$ & cell-substrate junction organization & $106 / 18862$ & $8.58 \mathrm{E}-07$ & 0.00021942 \\
\hline $\mathrm{BP}$ & cornification & $113 / 18862$ & $1.32 \mathrm{E}-06$ & 0.00021942 \\
\hline $\mathrm{BP}$ & cell adhesion mediated by integrin & $72 / 18862$ & $1.38 \mathrm{E}-06$ & 0.00021942 \\
\hline $\mathrm{BP}$ & epidermal cell differentiation & $360 / 18862$ & $1.42 \mathrm{E}-06$ & 0.00021942 \\
\hline BP & formation of primary germ layer & $115 / 18862$ & $1.49 \mathrm{E}-06$ & 0.00021942 \\
\hline BP & keratinization & $225 / 18862$ & $1.53 \mathrm{E}-06$ & 0.00021942 \\
\hline $\mathrm{BP}$ & cell-matrix adhesion & $230 / 18862$ & $1.84 \mathrm{E}-06$ & 0.000241166 \\
\hline $\mathrm{BP}$ & gastrulation & $179 / 18862$ & $2.66 \mathrm{E}-06$ & 0.000321238 \\
\hline $\mathrm{BP}$ & extracellular matrix organization & $393 / 18862$ & $3.31 \mathrm{E}-06$ & 0.000350118 \\
\hline $\mathrm{BP}$ & extracellular structure organization & $394 / 18862$ & $3.39 \mathrm{E}-06$ & 0.000350118 \\
\hline $\mathrm{BP}$ & external encapsulating structure organization & $396 / 18862$ & $3.56 \mathrm{E}-06$ & 0.000350118 \\
\hline $\mathrm{BP}$ & cell-substrate adhesion & $359 / 18862$ & $9.94 \mathrm{E}-06$ & 0.000919336 \\
\hline BP & mesodermal cell differentiation & $32 / 18862$ & $1.72 \mathrm{E}-05$ & 0.001499725 \\
\hline $\mathrm{BP}$ & mesoderm formation & $68 / 18862$ & $2.02 \mathrm{E}-05$ & 0.001674835 \\
\hline $\mathrm{BP}$ & mesoderm morphogenesis & $70 / 18862$ & 2.33E-05 & 0.001833235 \\
\hline $\mathrm{BP}$ & positive regulation of chemotaxis & $139 / 18862$ & $6.09 \mathrm{E}-05$ & 0.004395847 \\
\hline $\mathrm{BP}$ & epithelial cell migration & $357 / 18862$ & $6.15 \mathrm{E}-05$ & 0.004395847 \\
\hline $\mathrm{BP}$ & epithelium migration & $360 / 18862$ & $6.56 \mathrm{E}-05$ & 0.004483738 \\
\hline $\mathrm{BP}$ & negative regulation of anoikis & $17 / 18862$ & 7.27E-05 & 0.004584778 \\
\hline BP & tissue migration & $365 / 18862$ & 7.29E-05 & 0.004584778 \\
\hline $\mathrm{BP}$ & keratinocyte proliferation & $48 / 18862$ & $8.75 \mathrm{E}-05$ & 0.005293053 \\
\hline $\mathrm{BP}$ & ameboidal-type cell migration & $473 / 18862$ & 0.000102639 & 0.005822652 \\
\hline $\mathrm{BP}$ & entry into host & $153 / 18862$ & 0.00010367 & 0.005822652 \\
\hline $\mathrm{BP}$ & integrin-mediated signaling pathway & $106 / 18862$ & 0.000170071 & 0.009222742 \\
\hline $\mathrm{BP}$ & response to prostaglandin $\mathrm{E}$ & $23 / 18862$ & 0.000185292 & 0.009713186 \\
\hline $\mathrm{BP}$ & establishment of skin barrier & $24 / 18862$ & 0.000211015 & 0.010283511 \\
\hline $\mathrm{BP}$ & regulation of anoikis & $24 / 18862$ & 0.000211015 & 0.010283511 \\
\hline $\mathrm{BP}$ & movement in host environment & $175 / 18862$ & 0.000215789 & 0.010283511 \\
\hline $\mathrm{BP}$ & cell junction assembly & $425 / 18862$ & 0.00022915 & 0.010599087 \\
\hline $\mathrm{BP}$ & regulation of water loss via skin & $26 / 18862$ & 0.00026916 & 0.012093978 \\
\hline $\mathrm{BP}$ & positive regulation of cell projection organization & $344 / 18862$ & 0.000277513 & 0.012122947 \\
\hline $\mathrm{BP}$ & positive regulation of granulocyte chemotaxis & $27 / 18862$ & 0.000301738 & 0.012824934 \\
\hline $\mathrm{BP}$ & mesoderm development & $123 / 18862$ & 0.0003398 & 0.014062637 \\
\hline $\mathrm{BP}$ & response to prostaglandin & $30 / 18862$ & 0.000414413 & 0.016710737 \\
\hline $\mathrm{BP}$ & anoikis & $34 / 18862$ & 0.000602246 & 0.023677781 \\
\hline $\mathrm{BP}$ & biological process involved in interaction with host & $219 / 18862$ & 0.000710972 & 0.027270667 \\
\hline BP & cell chemotaxis & $306 / 18862$ & 0.000745332 & 0.027907915 \\
\hline $\mathrm{BP}$ & regulation of keratinocyte proliferation & $37 / 18862$ & 0.000773772 & 0.028299038 \\
\hline $\mathrm{BP}$ & regulation of chemotaxis & $224 / 18862$ & 0.000799698 & 0.028582522 \\
\hline $\mathrm{BP}$ & bone remodeling & $89 / 18862$ & 0.000943054 & 0.03295725 \\
\hline $\mathrm{BP}$ & regulation of dopaminergic neuron differentiation & $10 / 18862$ & 0.001032363 & 0.035294066 \\
\hline $\mathrm{BP}$ & epithelial cell proliferation & $428 / 18862$ & 0.00116202 & 0.038038774 \\
\hline $\mathrm{BP}$ & $\begin{array}{l}\text { regulation of dendritic cell antigen processing and } \\
\text { presentation }\end{array}$ & $11 / 18862$ & 0.001257775 & 0.038038774 \\
\hline $\mathrm{BP}$ & protein folding in endoplasmic reticulum & $11 / 18862$ & 0.001257775 & 0.038038774 \\
\hline $\mathrm{BP}$ & skin morphogenesis & $11 / 18862$ & 0.001257775 & 0.038038774 \\
\hline $\mathrm{BP}$ & dendritic cell apoptotic process & $11 / 18862$ & 0.001257775 & 0.038038774 \\
\hline $\mathrm{BP}$ & regulation of dendritic cell apoptotic process & $11 / 18862$ & 0.001257775 & 0.038038774 \\
\hline $\mathrm{BP}$ & endodermal cell differentiation & $44 / 18862$ & 0.001286801 & 0.038182347 \\
\hline
\end{tabular}




\begin{tabular}{|c|c|c|c|c|}
\hline $\mathrm{BP}$ & brown fat cell differentiation & $46 / 18862$ & 0.001464569 & 0.04265236 \\
\hline $\mathrm{BP}$ & establishment of $\mathrm{T}$ cell polarity & $12 / 18862$ & 0.001504544 & 0.043019868 \\
\hline BP & regulation of cell adhesion mediated by integrin & $48 / 18862$ & 0.001657031 & 0.04570258 \\
\hline BP & tissue homeostasis & $260 / 18862$ & 0.001717022 & 0.04570258 \\
\hline BP & regulation of granulocyte chemotaxis & $49 / 18862$ & 0.001758907 & 0.04570258 \\
\hline BP & establishment of lymphocyte polarity & 13/18862 & 0.001772461 & 0.04570258 \\
\hline $\mathrm{BP}$ & immunological synapse formation & $13 / 18862$ & 0.001772461 & 0.04570258 \\
\hline BP & regulation of insulin secretion & $178 / 18862$ & 0.001794325 & 0.04570258 \\
\hline $\mathrm{BP}$ & $\begin{array}{l}\text { positive regulation of plasma membrane bounded cell } \\
\text { projection assembly }\end{array}$ & $106 / 18862$ & 0.001801795 & 0.04570258 \\
\hline BP & regulation of bone remodeling & $51 / 18862$ & 0.001974208 & 0.049280987 \\
\hline $\mathrm{CC}$ & integrin complex & $31 / 19520$ & $1.38 \mathrm{E}-05$ & 0.000958944 \\
\hline $\mathrm{CC}$ & laminin complex & $12 / 19520$ & $2.23 \mathrm{E}-05$ & 0.000958944 \\
\hline $\mathrm{CC}$ & protein complex involved in cell adhesion & $36 / 19520$ & $2.53 \mathrm{E}-05$ & 0.000958944 \\
\hline $\mathrm{CC}$ & basement membrane & $94 / 19520$ & 8.65E-05 & 0.002459337 \\
\hline $\mathrm{CC}$ & basal part of cell & $258 / 19520$ & 0.000233992 & 0.005320244 \\
\hline $\mathrm{CC}$ & endoplasmic reticulum lumen & $306 / 19520$ & 0.000650914 & 0.012333107 \\
\hline $\mathrm{CC}$ & basal plasma membrane & $240 / 19520$ & 0.001014444 & 0.016475178 \\
\hline $\mathrm{CC}$ & cornified envelope & $45 / 19520$ & 0.001285224 & 0.016721371 \\
\hline $\mathrm{CC}$ & anchored component of membrane & $170 / 19520$ & 0.001323775 & 0.016721371 \\
\hline $\mathrm{CC}$ & neuronal dense core vesicle & $13 / 19520$ & 0.001692709 & 0.019243428 \\
\hline $\mathrm{CC}$ & costamere & $18 / 19520$ & 0.003269266 & 0.033787629 \\
\hline $\mathrm{CC}$ & intermediate filament & $215 / 19520$ & 0.00366975 & 0.034766056 \\
\hline $\mathrm{CC}$ & cell-substrate junction & $423 / 19520$ & 0.004089977 & 0.035766605 \\
\hline $\mathrm{CC}$ & lamellipodium membrane & $22 / 19520$ & 0.004875244 & 0.039588448 \\
\hline $\mathrm{CC}$ & cortical actin cytoskeleton & $78 / 19520$ & 0.006154032 & 0.045305642 \\
\hline $\mathrm{CC}$ & apical plasma membrane & $351 / 19520$ & 0.006659117 & 0.045305642 \\
\hline $\mathrm{CC}$ & microvillus membrane & $26 / 19520$ & 0.006774871 & 0.045305642 \\
\hline $\mathrm{CC}$ & intermediate filament cytoskeleton & $256 / 19520$ & 0.007604382 & 0.046857122 \\
\hline $\mathrm{CC}$ & dense core granule & 28/19520 & 0.007831213 & 0.046857122 \\
\hline $\mathrm{CC}$ & cell-cell junction & $485 / 19520$ & 0.008465165 & 0.04811778 \\
\hline
\end{tabular}

\section{Supplementary Table 5B. KEGG enrichment analysis.}

\begin{tabular}{llccc}
\hline ID & \multicolumn{1}{c}{ Description } & BgRatio & $\boldsymbol{p}$ value & $\boldsymbol{q}$ value \\
\hline hsa04512 & ECM-receptor interaction & $88 / 8105$ & $3.28 \mathrm{E}-07$ & $3.11 \mathrm{E}-05$ \\
hsa04510 & Focal adhesion & $201 / 8105$ & $8.56 \mathrm{E}-06$ & 0.000370605 \\
hsa04151 & PI3K-Akt signaling pathway & $354 / 8105$ & $1.17 \mathrm{E}-05$ & 0.000370605 \\
hsa05222 & Small cell lung cancer & $92 / 8105$ & 0.00011567 & 0.002739557 \\
hsa05412 & Arrhythmogenic right ventricular cardiomyopathy & $77 / 8105$ & 0.000701775 & 0.01329678 \\
hsa05410 & Hypertrophic cardiomyopathy & $90 / 8105$ & 0.001260558 & 0.019074857 \\
hsa05414 & Dilated cardiomyopathy & $96 / 8105$ & 0.001601543 & 0.019074857 \\
hsa05165 & Human papillomavirus infection & $331 / 8105$ & 0.001610766 & 0.019074857 \\
\hline
\end{tabular}


Supplementary Table 6A. GSEA of high risk.

\begin{tabular}{|c|c|c|c|c|}
\hline NAME & ES & NES & NOM $p$-val & FDR $q$-val \\
\hline KEGG_PENTOSE_PHOSPHATE_PATHWAY & 0.5729152 & 1.6310743 & 0.01953125 & 1 \\
\hline KEGG_PROTEASOME & 0.6784165 & 1.6303458 & 0.049701788 & 0.6821798 \\
\hline $\begin{array}{l}\text { KEGG_GLYCOSPHINGOLIPID_BIOSYNTHESIS_LACTO_AND_NEOLACTO_ } \\
\text { SERIES }\end{array}$ & 0.5090886 & 1.5907345 & 0.024952015 & 0.6408247 \\
\hline KEGG_THYROID_CANCER & 0.53489053 & 1.5439887 & 0.05179283 & 0.6907832 \\
\hline KEGG_P53_SIGNALING_PATHWAY & 0.47881857 & 1.5324117 & 0.04347826 & 0.60003185 \\
\hline KEGG_GLYCOLYSIS_GLUCONEOGENESIS & 0.47841245 & 1.5322174 & 0.037698414 & 0.50075066 \\
\hline KEGG_ADHERENS_JUNCTION & 0.4795818 & 1.5175084 & 0.0662768 & 0.47806197 \\
\hline KEGG_STEROID_BIOSYNTHESIS & 0.6314558 & 1.4914162 & 0.09486166 & 0.4986435 \\
\hline KEGG_PATHOGENIC_ESCHERICHIA_COLI_INFECTION & 0.48299125 & 1.4645706 & 0.086105675 & 0.524178 \\
\hline KEGG_TIGHT_JUNCTION & 0.39693546 & 1.4420464 & 0.063872255 & 0.54062873 \\
\hline KEGG_AMINOACYL_TRNA_BIOSYNTHESIS & 0.5580433 & 1.4407 & 0.11516315 & 0.49625063 \\
\hline KEGG_STARCH_AND_SUCROSE_METABOLISM & 0.46116272 & 1.4073405 & 0.08583691 & 0.5482185 \\
\hline KEGG_GALACTOSE_METABOLISM & 0.48794708 & 1.3951346 & 0.091617934 & 0.53853256 \\
\hline KEGG_CELL_CYCLE & 0.4647909 & 1.3540881 & 0.19960861 & 0.61424387 \\
\hline KEGG_AXON_GUIDANCE & 0.3714874 & 1.3263278 & 0.10852713 & 0.6551905 \\
\hline KEGG_BASE_EXCISION_REPAIR & 0.5224427 & 1.3245112 & 0.1809145 & 0.6192906 \\
\hline KEGG_O_GLYCAN_BIOSYNTHESIS & 0.45017973 & 1.321248 & 0.1764706 & 0.5923887 \\
\hline KEGG_PORPHYRIN_AND_CHLOROPHYLL_METABOLISM & 0.42830938 & 1.3130741 & 0.13465346 & 0.5810344 \\
\hline KEGG_GLYCOSAMINOGLYCAN_BIOSYNTHESIS_KERATAN_SULFATE & 0.48650512 & 1.3112824 & 0.13765182 & 0.55493397 \\
\hline KEGG_PENTOSE_AND_GLUCURONATE_INTERCONVERSIONS & 0.46371907 & 1.2722654 & 0.18218623 & 0.62946343 \\
\hline KEGG_BLADDER_CANCER & 0.39896894 & 1.256486 & 0.18992248 & 0.6436727 \\
\hline KEGG_REGULATION_OF_ACTIN_CYTOSKELETON & 0.33413285 & 1.250563 & 0.17105263 & 0.62979627 \\
\hline KEGG_PANCREATIC_CANCER & 0.39570457 & 1.2432532 & 0.22896282 & 0.6211923 \\
\hline KEGG_PATHWAYS_IN_CANCER & 0.33537713 & 1.2430347 & 0.17017208 & 0.59580684 \\
\hline KEGG_DRUG_METABOLISM_OTHER_ENZYMES & 0.40908697 & 1.2375876 & 0.1609658 & 0.58401114 \\
\hline KEGG_SMALL_CELL_LUNG_CANCER & 0.3896531 & 1.2231851 & 0.22178218 & 0.59402245 \\
\hline KEGG_ENDOCYTOSIS & 0.3299927 & 1.2194865 & 0.20610687 & 0.58074325 \\
\hline KEGG_ONE_CARBON_POOL_BY_FOLATE & 0.47091427 & 1.2165351 & 0.256167 & 0.5663879 \\
\hline KEGG_AMINO_SUGAR_AND_NUCLEOTIDE_SUGAR_METABOLISM & 0.4007442 & 1.2126254 & 0.23745173 & 0.55516595 \\
\hline KEGG_N_GLYCAN_BIOSYNTHESIS & 0.40781587 & 1.2106607 & 0.23287672 & 0.5410943 \\
\hline KEGG_ASCORBATE_AND_ALDARATE_METABOLISM & 0.45372823 & 1.2069958 & 0.2371134 & 0.530202 \\
\hline KEGG_DNA_REPLICATION & 0.50567645 & 1.1796668 & 0.35166994 & 0.56995404 \\
\hline KEGG_OOCYTE_MEIOSIS & 0.36010596 & 1.1793286 & 0.26061776 & 0.55347526 \\
\hline KEGG_SYSTEMIC_LUPUS_ERYTHEMATOSUS & 0.37165263 & 1.1768961 & 0.25851703 & 0.54163045 \\
\hline KEGG_FRUCTOSE_AND_MANNOSE_METABOLISM & 0.39953077 & 1.1730746 & 0.29766536 & 0.53443813 \\
\hline $\begin{array}{l}\text { KEGG_ARRHYTHMOGENIC_RIGHT_VENTRICULAR_CARDIOMYOPATHY } \\
\text { ARVC }\end{array}$ & 0.35322598 & 1.1730168 & 0.26061776 & 0.5197308 \\
\hline KEGG_FOCAL_ADHESION & 0.34690592 & 1.1704245 & 0.2751938 & 0.51039374 \\
\hline KEGG_MISMATCH_REPAIR & 0.4998743 & 1.1677153 & 0.3300199 & 0.50204176 \\
\hline KEGG_NOTCH_SIGNALING_PATHWAY & 0.35844958 & 1.1651915 & 0.25581396 & 0.49362785 \\
\hline KEGG_ECM_RECEPTOR_INTERACTION & 0.38675836 & 1.1465491 & 0.3151751 & 0.51444507 \\
\hline KEGG_PYRIMIDINE_METABOLISM & 0.35571525 & 1.1058619 & 0.34740883 & 0.5765829 \\
\hline KEGG_STEROID_HORMONE_BIOSYNTHESIS & 0.33638063 & 1.0779973 & 0.34631148 & 0.6170261 \\
\hline KEGG_BIOSYNTHESIS_OF_UNSATURATED_FATTY_ACIDS & 0.39363536 & 1.0769395 & 0.35416666 & 0.60520357 \\
\hline KEGG_ENDOMETRIAL_CANCER & 0.3395971 & 1.0718687 & 0.40151516 & 0.60124856 \\
\hline KEGG_GLUTATHIONE_METABOLISM & 0.32758725 & 1.0697683 & 0.35 & 0.5916402 \\
\hline KEGG_HOMOLOGOUS_RECOMBINATION & 0.42976084 & 1.0597887 & 0.44646466 & 0.59751785 \\
\hline KEGG_BASAL_CELL_CARCINOMA & 0.32655776 & 1.0506406 & 0.38491297 & 0.6011576 \\
\hline KEGG_CHRONIC_MYELOID_LEUKEMIA & 0.33301565 & 1.0484524 & 0.4165067 & 0.5925686 \\
\hline KEGG_WNT_SIGNALING_PATHWAY & 0.2844261 & 1.0387905 & 0.39961758 & 0.598086 \\
\hline KEGG_NUCLEOTIDE_EXCISION_REPAIR & 0.37913045 & 1.0309824 & 0.44656488 & 0.60022134 \\
\hline KEGG_RENAL_CELL_CARCINOMA & 0.3186963 & 1.0266781 & 0.41917294 & 0.59651726 \\
\hline KEGG_SPLICEOSOME & 0.36476433 & 1.0200957 & 0.4743833 & 0.5970973 \\
\hline
\end{tabular}


KEGG_PROSTATE_CANCER

KEGG_METABOLISM_OF_XENOBIOTICS_BY_CYTOCHROME_P450

KEGG_UBIQUITIN_MEDIATED_PROTEOLYSIS

KEGG_APOPTOSIS

KEGG_HYPERTROPHIC_CARDIOMYOPATHY_HCM

KEGG_VEGF_SIGNALING_PATHWAY

KEGG_RNA_DEGRADATION

KEGG_ALZHEIMERS_DISEASE

KEGG_RETINOL_METABOLISM

KEGG_ETHER_LIPID_METABOLISM

KEGG_MELANOMA

KEGG COLORECTAL CANCER

KEGG_CYSTEINE_AND_METHIONINE_METABOLISM

KEGG_PROTEIN_EXPORT

KEGG_TERPENOID_BACKBONE_BIOSYNTHESIS

KEGG_ARGININE_AND_PROLINE_METABOLISM

KEGG_BASAL_TRANSCRIPTION_FACTORS

KEGG_CITRATE_CYCLE_TCA_CYCLE

KEGG_NOD_LIKE_RECEPTOR_SIGNALING_PATHWAY

KEGG_NITROGEN_METABOLISM

KEGG_DORSO_VENTRAL_AXIS_FORMATION

KEGG_TGF_BETA_SIGNALING_PATHWAY

KEGG_HUNTINGTONS_DISEASE

KEGG_PEROXISOME

KEGG_LINOLEIC_ACID_METABOLISM

KEGG_ANTIGEN_PROCESSING_AND_PRESENTATION

KEGG_OXIDATIVE_PHOSPHORYLATION
KEGG_DRUG_METABOLISM_CYTOCHROME_P450

KEGG_LONG_TERM_POTENTIATION

\begin{tabular}{cccc}
0.30396676 & 1.0045717 & 0.433526 & 0.6138756 \\
0.31419396 & 0.9750271 & 0.4947589 & 0.6572137 \\
0.30457303 & 0.9725739 & 0.4952199 & 0.6495022 \\
0.30550128 & 0.9666593 & 0.5116279 & 0.6480138 \\
0.2806289 & 0.9614698 & 0.5190381 & 0.6459331 \\
0.27282158 & 0.9604114 & 0.5095785 & 0.63673884 \\
0.3311516 & 0.95151705 & 0.54285717 & 0.641828 \\
0.30191407 & 0.9506232 & 0.5248509 & 0.632659 \\
0.3078011 & 0.93862295 & 0.53503186 & 0.6427308 \\
0.2848933 & 0.92489564 & 0.5694165 & 0.65457636 \\
0.25767887 & 0.9193458 & 0.5755814 & 0.65356475 \\
0.28481606 & 0.9170352 & 0.54990584 & 0.64734876 \\
0.2772554 & 0.91319263 & 0.5952849 & 0.6442672 \\
0.3686309 & 0.89727354 & 0.59029126 & 0.65978324 \\
0.27977046 & 0.895435 & 0.61349696 & 0.65332603 \\
0.37947118 & 0.88096434 & 0.59100205 & 0.6673157 \\
0.265575 & 0.87706816 & 0.6404715 & 0.66389406 \\
0.25249606 & 0.8637797 & 0.6546906 & 0.67669934 \\
0.28742987 & 0.8605561 & 0.62081784 & 0.67225385 \\
0.33972847 & 0.8536729 & 0.60240966 & 0.67510945 \\
0.27057242 & 0.8370338 & 0.6673077 & 0.6935009 \\
0.27890974 & 0.82567173 & 0.75390625 & 0.70317525 \\
0.28094056 & 0.8064852 & 0.73410404 & 0.72584325 \\
0.24235316 & 0.7868584 & 0.71881187 & 0.7473405 \\
0.24811034 & 0.77978605 & 0.6855469 & 0.7484468 \\
0.23973116 & 0.75253385 & 0.7090559 & 0.7813006 \\
0.24497381 & 0.6923127 & 0.8792757 & 0.8565561 \\
0.23718034 & 0.6906942 & 0.814 & 0.84799135 \\
0.16179605 & 0.4302852 & 0.9700599 & 0.9947666 \\
\hline & & & \\
0
\end{tabular}

\section{Supplementary Table 6B. GSEA of low risk.}

\begin{tabular}{|c|c|c|c|c|}
\hline NAME & ES & NES & NOM $p$-val & FDR $q$-val \\
\hline KEGG_NEUROACTIVE_LIGAND_RECEPTOR_INTERACTION & -0.5290096 & -1.890673 & 0 & 0.07818665 \\
\hline KEGG_TYPE_II_DIABETES_MELLITUS & -0.53263277 & -1.7101595 & 0.003976143 & 0.41124317 \\
\hline KEGG_CALCIUM_SIGNALING_PATHWAY & -0.47805348 & -1.7010419 & 0 & 0.3046739 \\
\hline KEGG_TRYPTOPHAN_METABOLISM & -0.5109064 & -1.611668 & 0.0125 & 0.49959582 \\
\hline KEGG_GLYCINE_SERINE_AND_THREONINE_METABOLISM & -0.5354933 & -1.5545669 & 0.045009784 & 0.6258049 \\
\hline KEGG_VASCULAR_SMOOTH_MUSCLE_CONTRACTION & -0.45131353 & -1.5381501 & 0.033970278 & 0.5840838 \\
\hline KEGG_TASTE_TRANSDUCTION & -0.47686335 & -1.5074612 & 0.050632913 & 0.61628556 \\
\hline KEGG_HEMATOPOIETIC_CELL_LINEAGE & -0.5428187 & -1.4974189 & 0.08730159 & 0.57271385 \\
\hline KEGG_PRIMARY_IMMUNODEFICIENCY & -0.6386303 & -1.4330411 & 0.18431373 & 0.75888455 \\
\hline KEGG_JAK_STAT_SIGNALING_PATHWAY & -0.43019027 & -1.4310992 & 0.103658535 & 0.69109493 \\
\hline KEGG_ABC_TRANSPORTERS & -0.44498968 & -1.4232751 & 0.06841046 & 0.65386295 \\
\hline KEGG_ADIPOCYTOKINE_SIGNALING_PATHWAY & -0.4124259 & -1.4004673 & 0.07692308 & 0.6760876 \\
\hline KEGG_PHOSPHATIDYLINOSITOL_SIGNALING_SYSTEM & -0.43768927 & -1.3972843 & 0.09850107 & 0.634523 \\
\hline KEGG_GLYCOSPHINGOLIPID_BIOSYNTHESIS_GANGLIO_SERIES & -0.54259735 & -1.3912437 & 0.10261569 & 0.6088296 \\
\hline KEGG_INTESTINAL_IMMUNE_NETWORK_FOR_IGA_PRODUCTION & -0.5721416 & -1.3898985 & 0.17773438 & 0.5723439 \\
\hline KEGG_MATURITY_ONSET_DIABETES_OF_THE_YOUNG & -0.55656147 & -1.3844813 & 0.14003944 & 0.5516851 \\
\hline KEGG_CHEMOKINE_SIGNALING_PATHWAY & -0.4294434 & -1.3836561 & 0.12704918 & 0.52157277 \\
\hline KEGG_ASTHMA & -0.5758721 & -1.382636 & 0.17153996 & 0.49566385 \\
\hline KEGG_CELL_ADHESION_MOLECULES_CAMS & -0.43577835 & -1.362344 & 0.17540322 & 0.5201028 \\
\hline KEGG_CYTOKINE_CYTOKINE_RECEPTOR_INTERACTION & -0.40754113 & -1.3578213 & 0.12525667 & 0.5050087 \\
\hline KEGG_MTOR_SIGNALING_PATHWAY & -0.42019013 & -1.3523698 & 0.106471814 & 0.49395788 \\
\hline KEGG_REGULATION_OF_AUTOPHAGY & -0.42233485 & -1.3461435 & 0.10816327 & 0.48515308 \\
\hline KEGG_TYROSINE_METABOLISM & -0.42170665 & -1.341936 & 0.10766046 & 0.47379693 \\
\hline
\end{tabular}


KEGG_GLYCOSAMINOGLYCAN_DEGRADATION

KEGG_FC_EPSILON_RI_SIGNALING_PATHWAY

KEGG_PPAR_SIGNALING_PATHWAY

KEGG_LONG_TERM_DEPRESSION

KEGG_COMPLEMENT_AND_COAGULATION_CASCADES

KEGG_TYPE_I_DIABETES_MELLITUS

KEGG_PROXIMAL_TUBULE_BICARBONATE_RECLAMATION

KEGG_PRIMARY_BILE_ACID_BIOSYNTHESIS

KEGG GNRH SIGNALING PATHWAY

KEGG INOSITOL PHOSPHATE METABOLISM

KEGG_MAPK_SIGNALING_PATHWAY

KEGG_ALDOSTERONE_REGULATED_SODIUM_REABSORPTION

KEGG_T_CELL_RECEPTOR_SIGNALING_PATHWAY

KEGG_GLYCOSAMINOGLYCAN_BIOSYNTHESIS_CHONDROITIN_SULFATE

KEGG_NICOTINATE_AND_NICOTINAMIDE_METABOLISM

KEGG_AUTOIMMUNE_THYROID_DISEASE

KEGG_MELANOGENESIS

KEGG_ALLOGRAFT_REJECTION

KEGG_GAP_JUNCTION

KEGG_FATTY_ACID_METABOLISM

KEGG_SELENOAMINO_ACID_METABOLISM

KEGG BETA ALANINE METABOLISM

KEGG_GLYCEROPHOSPHOLIPID_METABOLISM

KEGG OLFACTORY TRANSDUCTION

KEGG PRION DISEASES

KEGG_INSULIN_SIGNALING_PATHWAY

KEGG_BUTANOATE_METABOLISM

KEGG_PANTOTHENATE_AND_COA_BIOSYNTHESIS

KEGG_CARDIAC_MUSCLE_CONTRACTION

KEGG_PROGESTERONE_MEDIATED_OOCYTE_MATURATION

KEGG_VALINE_LEUCINE_AND_ISOLEUCINE_DEGRADATION

KEGG_DILATED_CARDIOMYOPATHY

KEGG_EPITHELIAL_CELL_SIGNALING_IN_HELICOBACTER_PYLORI_ INFECTION

KEGG_GRAFT_VERSUS_HOST_DISEASE

KEGG_LYSINE_DEGRADATION

KEGG_FC_GAMMA_R_MEDIATED_PHAGOCYTOSIS

KEGG_GLYCOSAMINOGLYCAN_BIOSYNTHESIS_HEPARAN_SULFATE

KEGG_ARACHIDONIC_ACID_METABOLISM

KEGG_RIBOFLAVIN_METABOLISM

KEGG_B_CELL_RECEPTOR_SIGNALING_PATHWAY

KEGG_PHENYLALANINE_METABOLISM

KEGG_RENIN_ANGIOTENSIN_SYSTEM

KEGG_HISTIDINE_METABOLISM

KEGG_LYSOSOME

KEGG_VIBRIO_CHOLERAE_INFECTION

KEGG_PURINE_METABOLISM

KEGG_RNA_POLYMERASE

KEGG_NEUROTROPHIN_SIGNALING_PATHWAY

KEGG_ACUTE_MYELOID_LEUKEMIA

KEGG_AMYOTROPHIC_LATERAL_SCLEROSIS_ALS

KEGG_NON_SMALL_CELL_LUNG_CANCER

KEGG_LEUKOCYTE_TRANSENDOTHELIAL_MIGRATION

KEGG ERBB SIGNALING PATHWAY

KEGG_HEDGEHOG_SIGNALING_PATHWAY

KEGG_NATURAL_KILLER_CELL_MEDIATED_CYTOTOXICITY

KEGG_SPHINGOLIPID_METABOLISM

\begin{tabular}{|c|c|c|c|}
\hline-0.48054728 & -1.3278168 & 49 & ונס \\
\hline-0.39328453 & -1.3148739 & 0.15212981 & 0.4949966 \\
\hline-0.38816133 & -1.297917 & 0.1399177 & 0.51296306 \\
\hline-0.36285532 & -1.2761356 & .13279678 & 0.5412 \\
\hline-0.3989361 & -1.263181 & .16384181 & 0.5521064 \\
\hline-0.4928752 & -1.2604029 & 0.26732674 & 0.53883076 \\
\hline-0.44412115 & -1.2592758 & 0.18590999 & 0.522951 \\
\hline-0.49527532 & -1.2533015 & .18442623 & 0.51886904 \\
\hline-0.34357572 & -1.2519171 & 0.14784394 & 0.50569147 \\
\hline-0.39771664 & -1.2419469 & 0.21920668 & 0.51269734 \\
\hline-0.32389942 & -1.2344974 & 0.1764706 & 0.51308984 \\
\hline-0.3750422 & -1.22868 & 0.16359918 & 0.5105368 \\
\hline-0.411573 & -1.2120905 & 0.28456914 & 0.5295486 \\
\hline-0.45656192 & -1.206142 & .2774451 & 0.52710754 \\
\hline-0.38467285 & -1.2003758 & 0.23868313 & 0.52426314 \\
\hline-0.43872103 & -1.1698861 & 0.31547618 & 0.57136863 \\
\hline-0.3255055 & -1.1616304 & 0.23982869 & 0.57462007 \\
\hline-0.5078549 & -1.158935 & 0.36399218 & 0.56604004 \\
\hline-0.3317633 & -1.1554563 & 0.26283368 & 0.55955046 \\
\hline-0.40320912 & -1.15 & 0.29012346 & 0.5516308 \\
\hline-0.37339255 & -1.1386981 & 0.30241936 & 0.56841093 \\
\hline-0.39741 & -1.1361926 & 0.28252032 & 0.5608648 \\
\hline-0.31059223 & -1.1272689 & 0.26612905 & 0.56516355 \\
\hline-0.24886155 & -1.115168 & 0.22376238 & 0.57648504 \\
\hline-0.36 & -1.1 & 5 & 344 \\
\hline-0.3109605 & -1.1121604 & 0.3268817 & 0.5585135 \\
\hline-0.37009233 & -1.0814086 & 0.36491936 & 0.6072234 \\
\hline-0.37421823 & -1.0770823 & 0.3530572 & 0.6036107 \\
\hline-0.32574925 & -1.0768429 & 0.371134 & 0.5923154 \\
\hline-0.32766244 & -1.0730956 & 0.36247334 & 0.588726 \\
\hline-0.37054572 & -1.0679052 & 0.37623763 & 0.5874844 \\
\hline-0.31053647 & -1.0668976 & 0.34879032 & 0.5784172 \\
\hline-0.31845626 & -1.0656122 & 0.36916837 & 0.5703242 \\
\hline-0.4773792 & -1.0647981 & 0.42629483 & 0.56208354 \\
\hline-0.3400369 & -1.0595781 & 0.39591837 & 0.5619305 \\
\hline-0.32370082 & -1.056988 & 0.3877551 & 0.55720764 \\
\hline-0.36602896 & -1.0548011 & 0.37708333 & 0.5525173 \\
\hline-0.30121955 & -1.0340339 & 0.39314517 & 0.57759076 \\
\hline-0.3628063 & -1.0269295 & 0.41041666 & 0.58104 \\
\hline-0.35677096 & -1.0201818 & 0.45039684 & 0.5839937 \\
\hline-0.3458501 & -1.0084561 & 0.44855967 & 0.59530926 \\
\hline-0.39185286 & -0.9946408 & 0.48336595 & 0.61027443 \\
\hline-0.32132426 & -0.9890151 & 0.48033127 & 0.6116145 \\
\hline-0.30735183 & -0.9859231 & 0.4526316 & 0.6080056 \\
\hline-0.2991553 & -0.9856829 & 0.4556701 & 0.59937316 \\
\hline-0.271922 & -0.98382556 & 0.46637744 & 0.5934177 \\
\hline-0.34659335 & -0.95722973 & 0.50988144 & 0.6307953 \\
\hline-0.27906525 & -0.92767113 & 0.56959313 & 0.67536575 \\
\hline-0.30859992 & -0.92660505 & 0.54037267 & 0.66776955 \\
\hline-0.27340278 & -0.92612875 & 0.5708419 & 0.6596064 \\
\hline-0.30022708 & -0.92514 & 0.55737704 & 0.65228117 \\
\hline-0.27998474 & -0.9202179 & 0.5386266 & 0.6523266 \\
\hline-0.26887137 & -0.91797024 & 0.5744235 & 0.6477343 \\
\hline-0.28201923 & -0.9156276 & 0.55737704 & 0.64300805 \\
\hline-0.28414455 & -0.90748185 & 0.54969573 & 0.6490106 \\
\hline-0.29363042 & -0.9023531 & 0.60162604 & 0.6489709 \\
\hline
\end{tabular}


KEGG_PROPANOATE_METABOLISM

KEGG_GLIOMA

KEGG_GLYCEROLIPID_METABOLISM

KEGG_OTHER_GLYCAN_DEGRADATION

KEGG_LEISHMANIA_INFECTION

KEGG_ALANINE_ASPARTATE_AND_GLUTAMATE_METABOLISM

KEGG_VIRAL_MYOCARDITIS

KEGG_TOLL_LIKE_RECEPTOR_SIGNALING_PATHWAY

KEGG RIG I LIKE RECEPTOR SIGNALING PATHWAY

KEGG_VASOPRESSIN_REGULATED_WATER_REABSORPTION

KEGG SNARE INTERACTIONS IN VESICULAR TRANSPORT

KEGG_PYRUVATE_METABOLISM

KEGG_GLYCOSYLPHOSPHATIDYLINOSITOL_GPI_ANCHOR_BIOSYNTHESIS

KEGG_ALPHA_LINOLENIC_ACID_METABOLISM

KEGG_GLYOXYLATE_AND_DICARBOXYLATE_METABOLISM

KEGG_CYTOSOLIC_DNA_SENSING_PATHWAY

KEGG_RIBOSOME

KEGG_PARKINSONS_DISEASE

\begin{tabular}{cccc}
-0.3202926 & -0.8933692 & 0.59356135 & 0.6564102 \\
-0.26588964 & -0.87776834 & 0.6012397 & 0.67394316 \\
-0.25562853 & -0.87741315 & 0.645749 & 0.66659164 \\
-0.3497702 & -0.8746694 & 0.5978947 & 0.6635369 \\
-0.31960237 & -0.8571332 & 0.6122449 & 0.6853992 \\
-0.26438203 & -0.8277334 & 0.71398747 & 0.72542256 \\
-0.27853227 & -0.82128996 & 0.62890625 & 0.7271384 \\
-0.25039133 & -0.80701625 & 0.66935486 & 0.7418337 \\
-0.24272378 & -0.7962348 & 0.71666664 & 0.7515454 \\
-0.257244 & -0.7952852 & 0.7171717 & 0.7445486 \\
-0.26335508 & -0.79454243 & 0.71369296 & 0.7376034 \\
-0.25223786 & -0.79080826 & 0.73140496 & 0.7351275 \\
-0.29210636 & -0.7644893 & 0.72938687 & 0.76874876 \\
-0.2534912 & -0.7415896 & 0.87829614 & 0.79504913 \\
-0.29077378 & -0.7335219 & 0.78644764 & 0.79881746 \\
-0.23144941 & -0.7221297 & 0.8114754 & 0.80624986 \\
-0.3269558 & -0.6639908 & 0.7683168 & 0.8751104 \\
-0.18312952 & -0.5185772 & 0.92785573 & 0.9770979 \\
\hline & & &
\end{tabular}

